\title{
Severe wellbore instability in a complex lithology formation necessitating casing while drilling and continuous circulation system
}

\author{
R. Ashena ${ }^{1}$ (1) $\cdot$ A. Elmgerbi ${ }^{2} \cdot$ V. Rasouli ${ }^{3} \cdot$ A. Ghalambor ${ }^{4} \cdot$ M. Rabiei $^{3} \cdot$ A. Bahrami $^{5}$
}

Received: 9 November 2019 / Accepted: 3 January 2020 / Published online: 16 January 2020

(c) The Author(s) 2020

\begin{abstract}
Most of drilling hole problems are attributed to wellbore stability issues which adversely cause excessive lost time and cost millions of dollars. The past drilling experiences in Kupal oilfield showed excessive mud losses, kick flows, tight holes and pipe stuck leading to repeated reaming, fishing and sidetracking. Most of the drilling-associated problems in this field

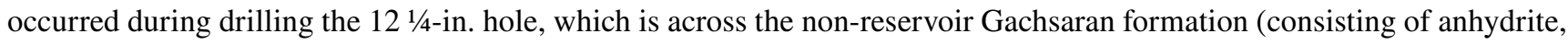
gypsum and marl with thin limestone layers). Mainly due to the lack of required formation evaluation data, no geomechanical studies of this formation have been conducted to date. In this work, first, we constructed a geomechanical model to investigate the root of the problems. This is a pioneer wellbore stability work for such a complex lithology formation which included finding the equations best-matching with core data and field observations. Finally, to overcome the field challenges and hole problems, the study proposes some field remedial actions. The results of the geomechanical modeling show that the pore pressure, shear and tensile failure gradients are greatly variable with the safe mud weight window becoming excessively narrow at some intervals. This accounts for the encountered wellbore stability issues as managing the mud weight in these situations requires several casing strings. To mitigate the extent of the problem, this study proposes the application of innovative drilling technologies including casing while drilling to eliminate the casing running time with potential reduction in drilling time, and continuous circulation system to prevent cuttings settling and kick flows during connections. These technologies are capable of elimination of the geomechanical part of the drilling delay (30\% of the average 77 drilling days) per well.
\end{abstract}

Keyword Wellbore stability · Non-reservoir complex lithology formation · Casing while drilling $\cdot$ Continuous circulation system

\section{Introduction}

Wellbore instability is one of the most critical challenges affecting not only the well construction phase, but the entire life cycle of a well. It is one of the major causes of nonproductive time (NPT) by causing issues such as borehole collapse, lost circulation, stuck pipe, sand production and other related well failure events. The NPT is any event that interrupts the progress of a planned operation causing a time

\footnotetext{
R. Ashena

ashena.rahman@gmail.com

Bear and Brook Consulting, Brisbane, Australia

2 University of Leoben, Leoben, Austria

3 University of North Dakota, Grand Forks, USA

4 Oil Center Research International, Lafayette, USA

5 University of Alberta, Edmonton, Canada
}

delay; it includes the total time needed to resolve the problem until the operation is resumed again from the point or the depth where the NPT event occurred.

The NPT typically accounts for up to $32 \%$ of drilling operations costs for deep-water wells (Halliburton 2016). Further, the geomechanical problems are associated with $40 \%$ of the drilling-related NPT in deep-water and other challenging environments (Schlumberger 2016). The total cost of geomechanics-related issues is multibillions of dollars (Aadnoy 2003). Fifty percent of this NPT is associated with geomechanics-related issues (stability, lost circulation, stuck pipe, etc.) accounting for nearly $11 \%$ of the drilling budget (Mody 2013).

In summary, the unexpected instability events increase risk, reduce safety, potentially harm crew and cause nonproductive time. Moreover, they are costly and can easily lead to a cost overrun if they occur frequently. Successful construction of wells containing trouble zones depends on 
accurate analysis of all available well data to deliver the well and its objectives. Being familiar with the local drilling environment can substantially reduce risk. Unfortunately, the drilling personnel often ignore the data and the corresponding learning observations from previous well construction attempts. The next well design is left unchanged expecting different results than what obtained from the previous failed attempt. Although this approach is illogical, it has too often been the norm in many offshore environments as proven by the amount of money spent on avoiding issues in drilling known and expected trouble zones (York et al. 2009). From this perspective, in this study, we investigated the root causes of wellbore instability in a critical Middle Eastern oilfield where severe drilling-associated problems occurred. The end-of-well reports of this field demonstrate that multiple problems related to wellbore instability occurred while drill-

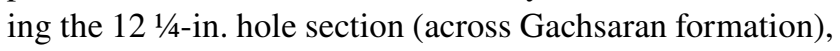
and they include severe mud losses, pit gains, tight holes, etc. There are currently no investigations of the problems of this field available in the literature. Since most of these instability events stem from geomechanical reasons, analyzing the geomechanical situation can help gain knowledge about when and where instability could occur and how to mitigate it.

In order to investigate the problems, first, the paper discusses the records of the drilling and non-productive-time (NPT) issues encountered in the field. Next, to associate the hole problems with geomechanical reasons, the mechanical earth model (MEM) of Gachsaran formation will be built and presented. Using the results of the MEM, wellbore stability analysis will be conducted and the geomechanical origin of the borehole problems including the narrow safe mud weight window will be detected. This is a pioneer wellbore stability work for a Gachsaran non-reservoir formation (with a complex lithology of anhydrite, gypsum and marl, with thin limestone layers) which is responsible for most of the wellbore stability issues and lost times (NPT). However, previous wellbore stability works in the region such as Aslannezhad et al. (2016) focused on the carbonate reservoir formations (which is not responsible for much lost times). Other wellbore stability works focused on sandstones such as Kolawole et al. (2018). There are several wellbore stability works on shales in recent years (Wang et al. 2014).

Finally, to mitigate the borehole problems, some potential solutions will be presented and discussed. These consist of application of innovative drilling techniques casing while drilling (CWD) and the continuous circulation system (CCS) to merge with the conventional method.

\section{Field of study}

Figure 1 shows the map of the area where Kupal oilfield is located in the Zagros region in the Middle East. Severe

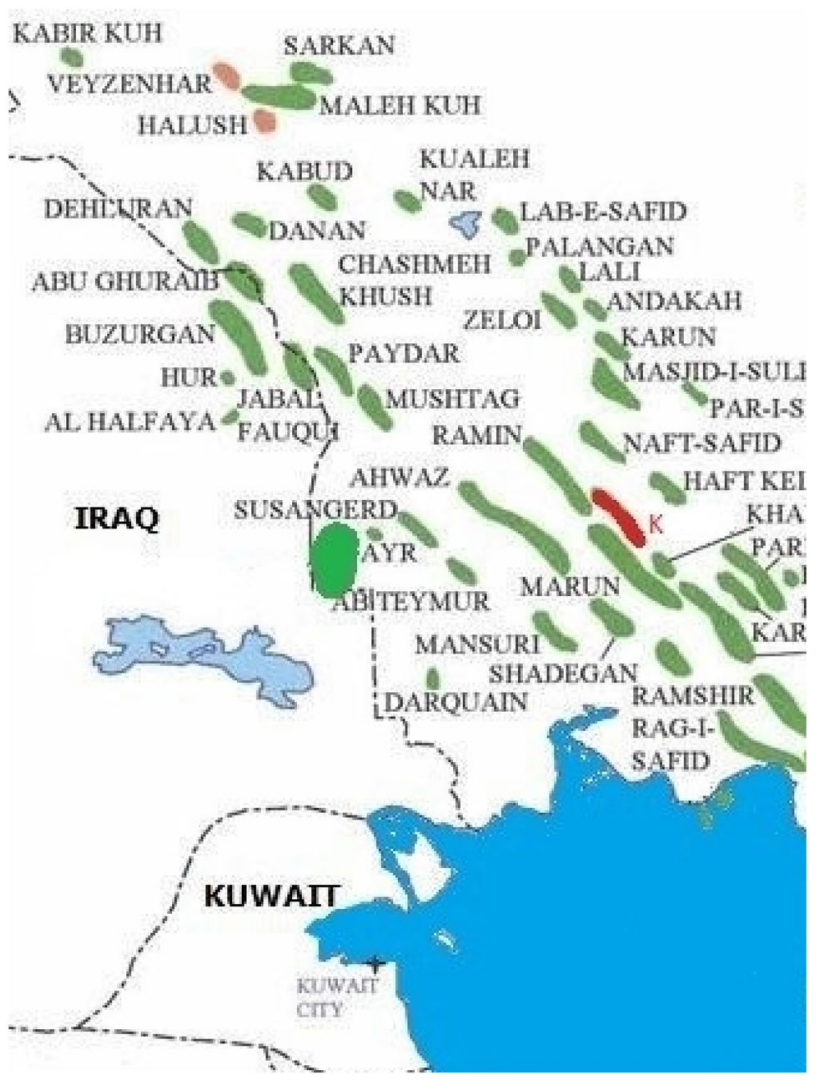

Fig. 1 The location of Kupal oilfield in the Middle East

drilling problems are encountered particularly during drilling wells in this field. The majority of hole problems in this field occur during drilling Gachsaran formation overlying the reservoir. This formation (which has a complex lithology consisting of anhydrite, gypsum, marl and thin limestone layers) is extremely abnormally pressured. Severe hole problems in drilling this formation are generally attributed to thick trouble zones, extremely high abnormal pore pressure (causing great differential pressure leading to differential pipe sticking). The necessity of overcoming extremely high pore pressure requires the use of greater percentage of weight materials (which in turn causes cuttings settling and stuck pipe). Furthermore, greater concentration of fractures than nearby fields causes more severe mud losses and lost circulation. The following subsections briefly review the commonly observed drilling problems (excessive mud losses and tight holes or stuck pipe) as observed in the field as well as indications of low-performance drilling (ROP and NPT).

\section{Excessive mud losses or possible gains}

In drilling the $12 \frac{1}{1 / 4}$-in. hole (Gachsaran formation), excessive mud losses and gains occur intermittently. Mud loss usually occurs due to induced-fracturing of the thin limestone 
layers interbedded in this formation. The pore pressure of Gachsaran formation, as will be estimated and discussed in the "Wellbore Stability Analysis" section, is excessively abnormal and close to $1 \mathrm{psi} / \mathrm{ft}$ (or greater). This is mainly attributed to the conversion of gypsum $\left(\mathrm{CaSO}_{4} \cdot 2 \mathrm{H}_{2} \mathrm{O}\right)$ to anhydrite $\left(\mathrm{CaSO}_{4}\right)$ releasing reaction water. Having the reservoir in a closed basin, the released water which has moved to the interbedded limestone layers becomes excessively over-pressured during geologic time. Therefore, when mud weights are not selected and adjusted appropriately, kick flows may occur.

This study chose 28 wells with reported mud losses for performing in-depth analysis (see Fig. 2). Several facts can be extracted from this figure, as follows:

1. The minimum mud loss occurred in well $\mathrm{Z} 2$ with $74 \mathrm{bbls}$, and the maximum mud loss occurred in well Z30 with 29,728 bbl.

2. Twenty-three wells ( $82 \%$ of the total wells) reported mud losses greater than $300 \mathrm{bbl}$.

3. It was observed that the magnitude of mud losses has dramatically increased during 2011-2017 (average of $6994 \mathrm{bbl}$ per well) compared to the earlier time with the average loss of $1085 \mathrm{bbl}$ per well.

In this field, several methods were tried aiming at mitigating the extreme mud losses. One of these methods was performed by maintaining the dynamic mud pressure, i.e., equivalent circulating density (ECD) greater than the formation pressure while the mud column pressure (hydrostatic pressure) is lower than the formation pore pressure. Finally, at the end of drilling, prior to tripping the drill string, they proceed to increase the (static) mud weight so that no kick flows may occur during tripping (although huge mud losses occurred and the well had to be filled-up). However, the main problem experienced in such instances was during connections when kick flows could occur, which made the crew expedite in making the connection (an unsafe practice). This study provides a solution to this practice, which can be successfully applied to most drilling operations in Kupal field.

In contrast, the pit gain, due to kick flow, is reported in only seven wells with the maximum value of $200 \mathrm{bbl}$ in wells Z26, Z30 and Z32, as presented in Fig. 3. Similar to the mud loss, the pit gain shows a significant increase during 2011-2017 (arithmetic average of $60 \mathrm{bbl}$ per well) compared to the average of $18.5 \mathrm{bbl}$ per well prior to this period. In this period, the significant anomalous increase in mud losses and decrease in drilling performance occurred due to improper drilling equipment used recently. Generally, some cases of kick flows were not reported because they were underground blowout (not observed or noticed at the surface), or for other reasons. An underground blowout is an occurrence of flow from a high-pressured formation which loses to an underground thief zone (low-pressured), which may not necessarily be observed at the surface.

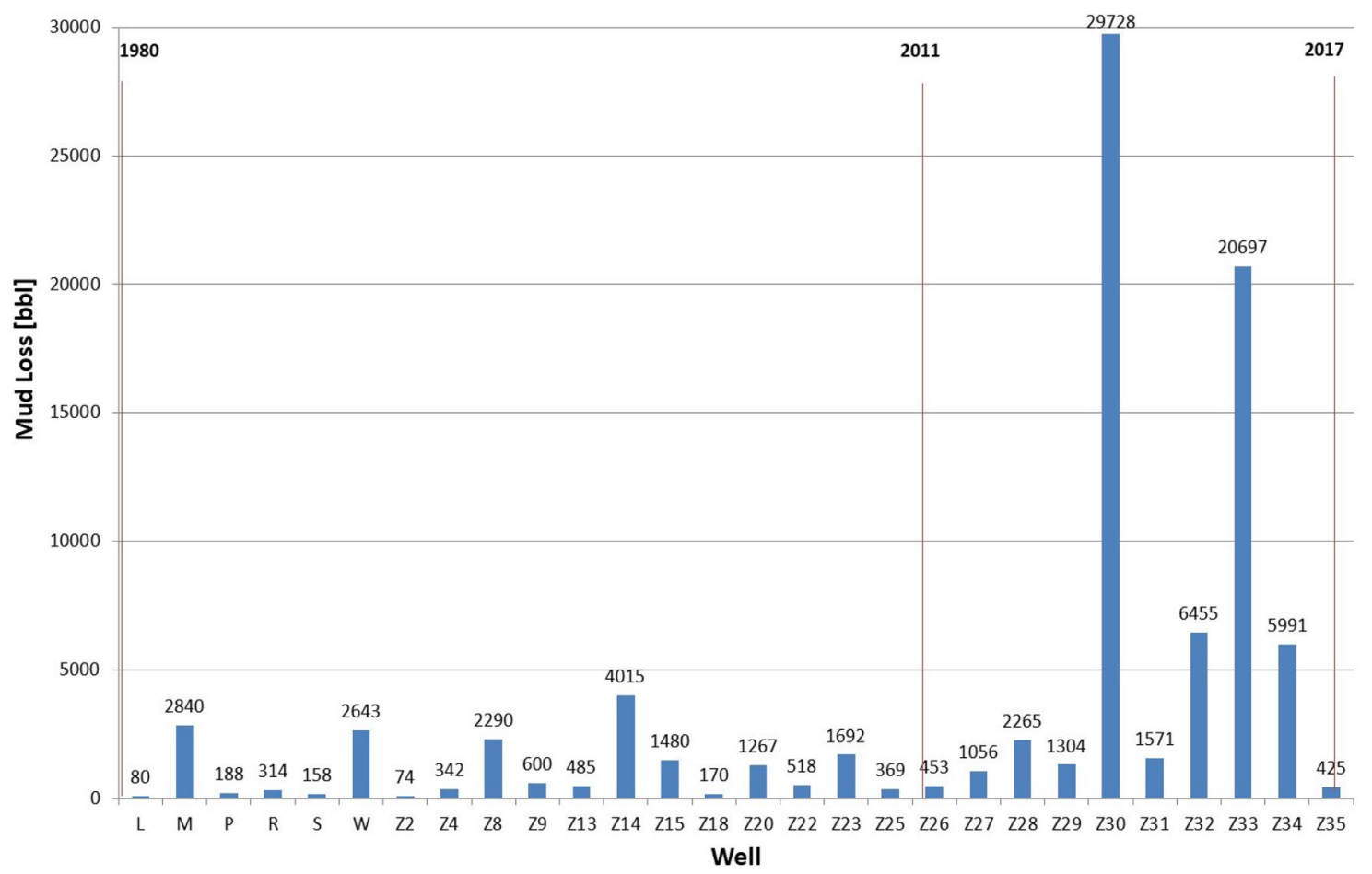

Fig. 2 Mud loss magnitudes occurring in Gachsaran formation in different wells of Kupal field 


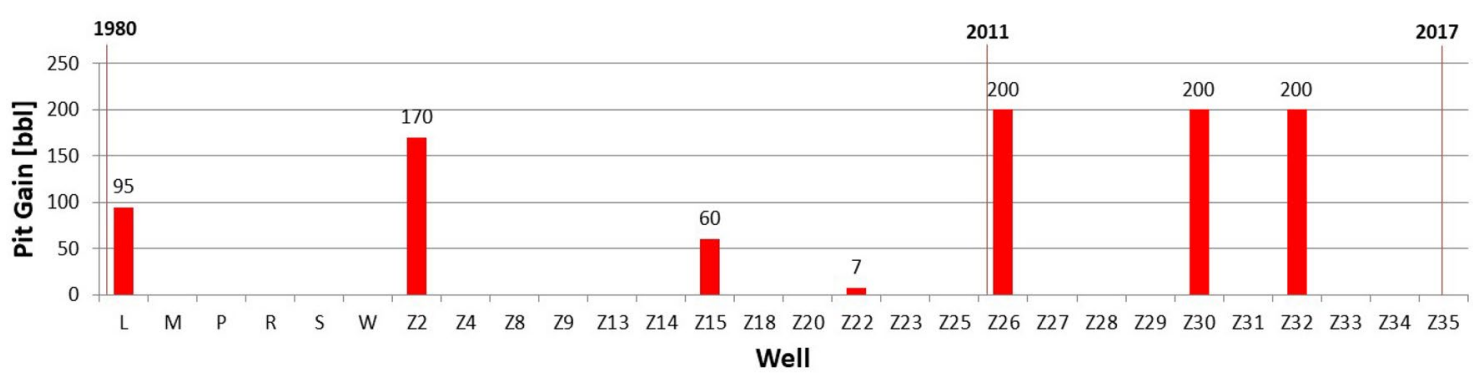

Fig. 3 Pit gains in Gachsaran formation in different wells of Kupal field

Review of the field reports indicates that in cases of mud loss where the driller lowered the mud weight for a small fraction of $0.025 \mathrm{ppg}$, it resulted in a noticeable kick flow. This suggests a greatly narrow safe mud weight window for drilling, justifying the initiative to conduct the geomechanical studies in this field. With the formation evaluation data becoming available from a recent well logging and coring into the Gachsaran formation, building the one-dimensional mechanical earth model (MEM) will now be possible.

\section{Tight holes and stuck-pipe}

In Kupal field, tight holes frequently occur in drilling the $121 / 4$-in. hole, followed by stuck pipe in some cases. The crew periodically conducts wash-and-reaming following drilling operations. As another consequence, the casing string becomes stuck during running in the hole (RIH) in numerous cases. Stuck occurrences in drilling this formation has led to costly operations such as long fishing operations or even sidetracking in many cases.

\section{Low drilling performance}

The average ROP values $(\mathrm{m} / \mathrm{h})$ of drilling the $121 / 4$-in. hole section for 35 wells are presented in Fig. 4. The following can be inferred from the figure:

1. The average ROP of seven wells (i.e., $20 \%$ of the total number of wells) is greater than $7.25 \mathrm{~m} / \mathrm{h}$, whereas in 20 wells (i.e., $57 \%$ of the total number of wells) the ROP is lower than $5 \mathrm{~m} / \mathrm{h}$.

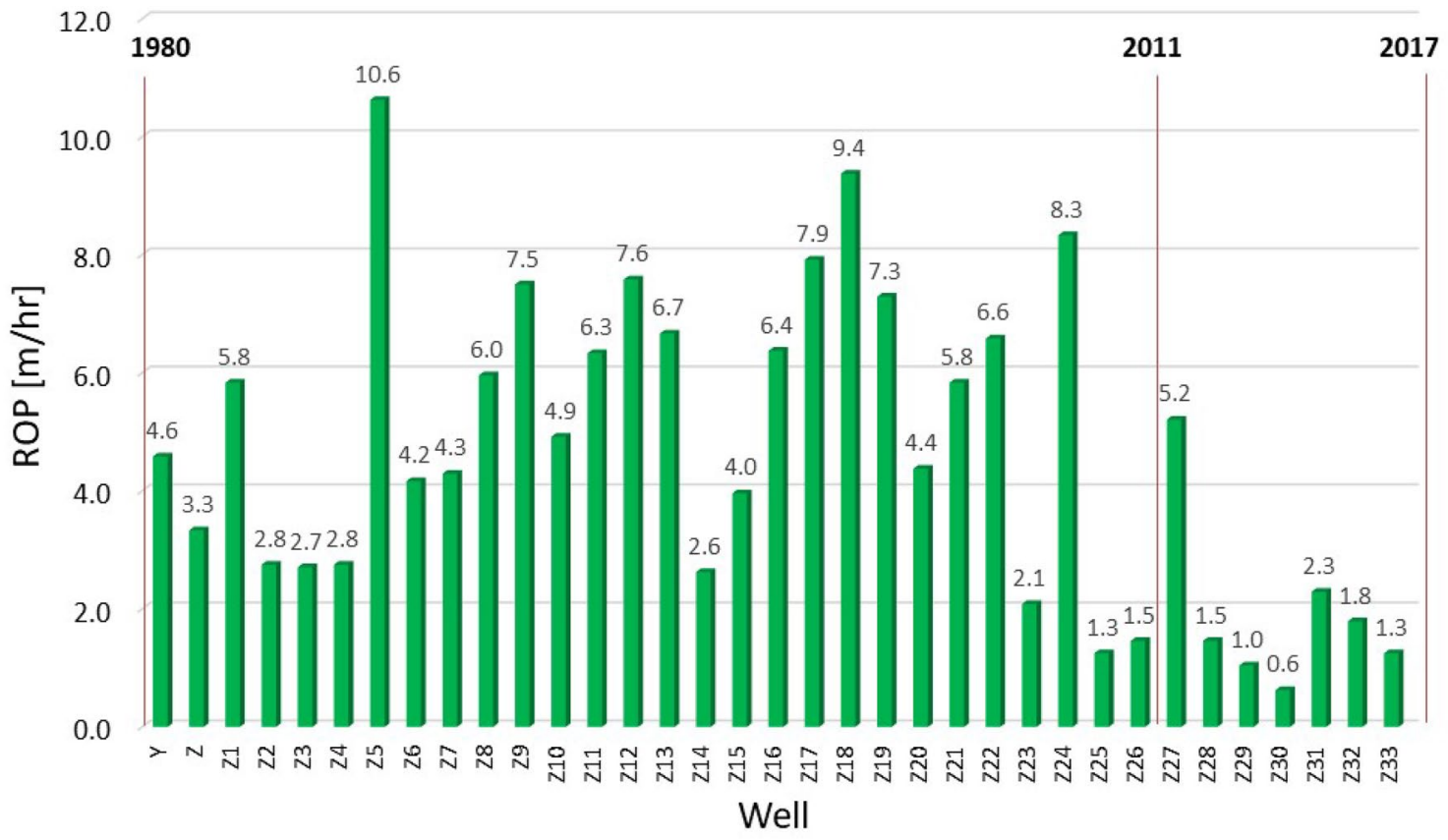

Fig. 4 The average ROP of drilling the 12 1/4-in. hole section (across Gachsaran formation) in 35 wells of Kupal field 
2. The ROP is lower than $1.5 \mathrm{~m} / \mathrm{h}$ for six wells drilled during 2011-2017 period (17\% of the total number of wells).

3. These data show the inefficiency in drilling due to nonoptimized drilling parameters and methods, use of inefficient equipment and materials including drilling bits, and inappropriate mud pumps. However, the tectonic activity of the field requires a full geomechanics study to identify the technical parameters resulting in inefficient drilling. Therefore, the drilling parameters require improvement to yield optimal ROPs, and the drilling method should be modified (to a more suitable one).

4. Comparing the ROP chart with the mud loss chart in the 12.25 hole size across Gachsaran formation, it is seen that the lesser the mud losses/gains, the greater the ROP. Some examples of excessively low ROP are observed in wells Z14 (loss), Z26 (gain), Z30 (loss), Z32 (loss) and $\mathrm{Z} 33$ (loss). The maximum average ROP is in well Z4 with $10.6 \mathrm{~m} / \mathrm{h}$.

\section{Drilling delays}

Figure 5 shows the drilling delays/time deviations for 32 investigated wells (nearly half of the total drilled wells in Kupal oilfield). As the selected wells targetted Asmari reservoir formation below Gachsaran formation, the drilling delays are related to the hole problems during drilling Gachsaran formation (12 1/4-in. hole). The drilling delay for each well (in rig days) is found by subtracting the predicted rig days from the actual rig days. Table 1 shows the average delays for three periods of pre-1980, 1980-2011 and 2011-2017. As Fig. 5 and Table 1 show, a moderate increase
Table 1 The average drilling delays/deviation in Kupal oilfield for the three periods of: (a) pre-1980, (b) 1980-2011 and (c) 2011-2017

\begin{tabular}{lccc}
\hline & $\begin{array}{l}\text { Number of } \\
\text { wells }\end{array}$ & Total delays & Average delays \\
\hline Before 1980 & 8 & 184 & 23 \\
$1980-2011$ & 26 & 789 & 30.3 \\
$2011-2017$ & 7 & 1212.5 & 173.2 \\
Total & 41 & 2185.5 & 53.3 \\
\hline
\end{tabular}

in the delay is seen from 60 days for pre-1980 period to around 48 days for the 1980-2011 period. However, it abruptly increased to around 173 days for the period of 2011-2017 due to various drilling issues. The average drilling delay/deviation in this field is 77 days. About $30 \%$ of the drilling delays have occurred due to geomechanical reasons, but the rest was due to waiting for equipment or materials.

In the following section, the study presents the wellbore stability analysis conducted in this field followed by proposed methods of drilling optimization.

\section{Wellbore stability analysis}

When a borehole is being drilled, the in situ stress state is disturbed. Depending on the field, it can potentially cause borehole stability issues (such as kick flows, tight hole, stuck pipe, breakouts and lost circulation), leading to NPT or drilling NPT. Using the data from well Z26 (the only well with data from Gachsaran formation), the 1-D MEM was constructed to evaluate the safe mud weight window. Figure 6

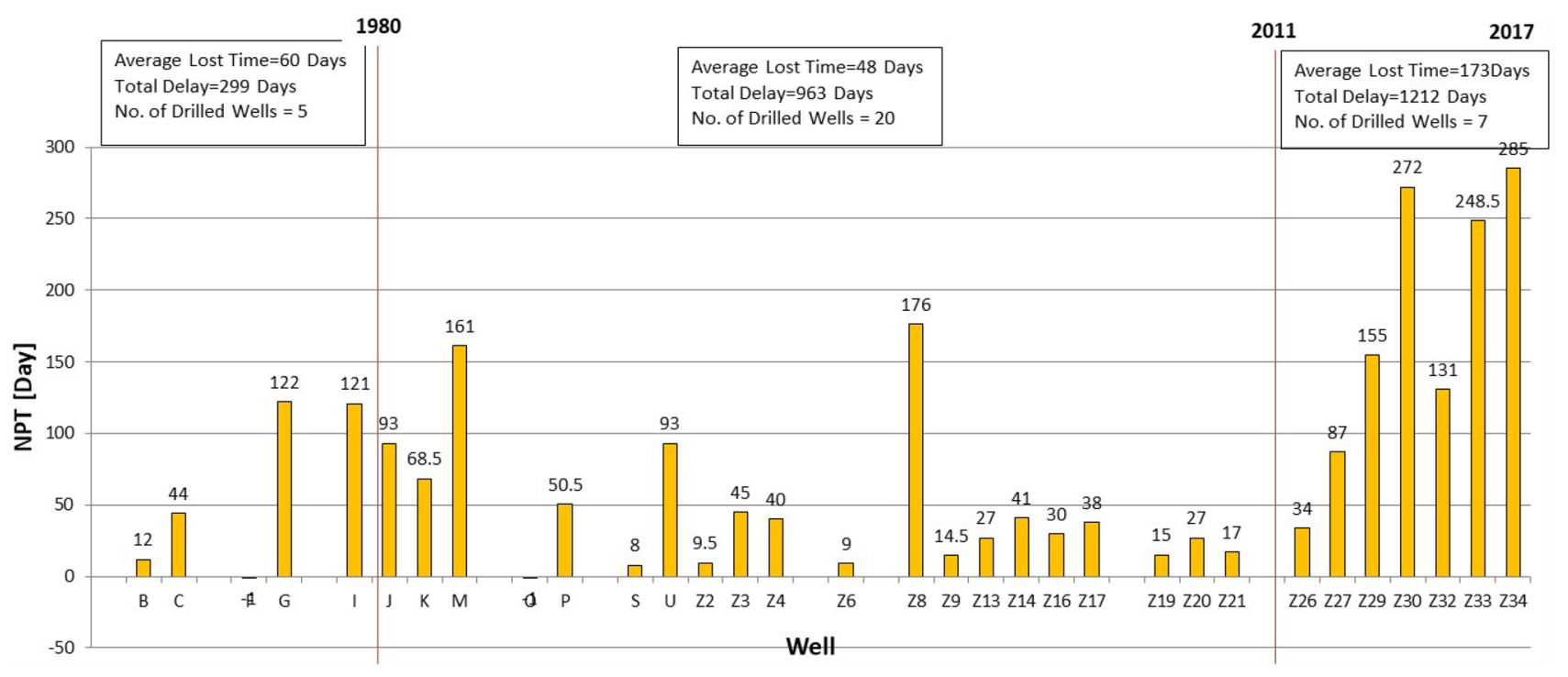

Fig. 5 Drilling delays/time deviations (for 32 wells in Kupal field) 


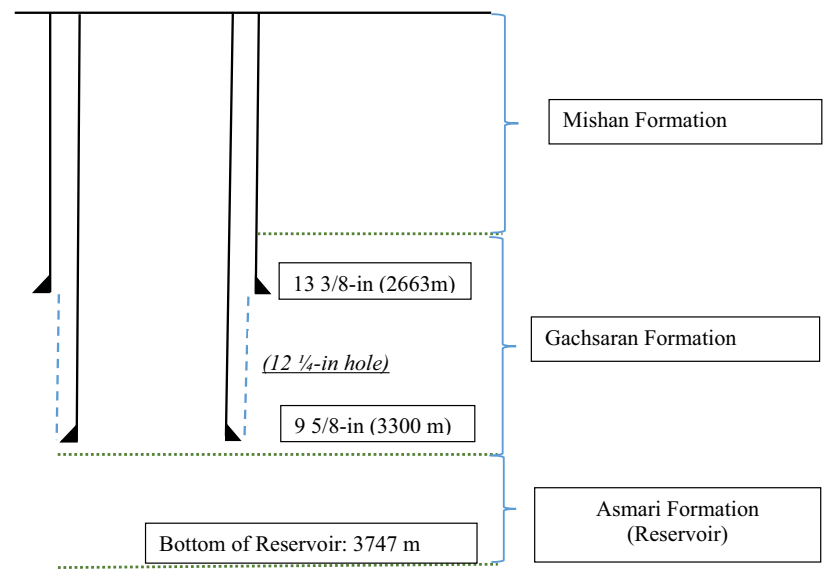

Fig. 6 Schematic of well Z26 of Kupal oilfield (for the 12 1/4-in. hole across Gachsaran formation) shows the schematic of well Z26. This is explained in detail in the following sections.

\section{Input data and parameters}

Table 2 shows the input data required for building the 1D-MEM. It includes well trajectory, petrophysical logs, drilling and mud parameters, core data and formation integrity data (leak-off or formation strength test). The interpreted petrophysical data are shown in Fig. 7. The core laboratory results available at three depths are provided in Table 3 with drilling and mud data presented in Table 4 . The interpretation of the cuttings analysis is given in Table 5 . The recorded data for the mud loss and kick flow occurrences are, respectively, listed in Tables 6 and 7. The image log of well Z26 (for the underlying reservoir formation) was available for investigating the directions of the horizontal in situ stresses. The breakouts (with an example in Fig. 8) indicate the direction of minimum horizontal stress of N75W (285 degrees from North), and the drilling-induced fractures indicate

Table 2 Input data used for constructing the MEM in well Z26 and in which evaluations, they were used

\begin{tabular}{|c|c|c|}
\hline & Data & Used for evaluation \\
\hline \multirow[t]{3}{*}{ Well trajectory } & $\begin{array}{l}\text { True vertical depth (TVD) or measured } \\
\text { depth (MD) }\end{array}$ & Depth (2700-3200 m) \\
\hline & Azimuth & Zero (Vertical well) \\
\hline & Inclination angle & Zero (Vertical well) \\
\hline \multirow[t]{8}{*}{ Petrophysical data } & Gamma ray GR & $V_{\text {shale }}$ (Used for $\varphi$ evaluation) \\
\hline & Density log & $\sigma_{\mathrm{v}}$ and $E_{\mathrm{d}}$ \\
\hline & Dipole sonic $\log \left(\Delta T_{\mathrm{c}}\right.$ and $\left.\Delta T_{\mathrm{s}}\right)$ & $E_{\mathrm{d}}, v$ and UCS \\
\hline & Neutron log NPHI & $\varnothing$ \\
\hline & Porosity $\emptyset$ & Internal friction angle, $\varphi$ \\
\hline & Lithology (interpreted) & Used in correlation for UCS, $E_{\mathrm{d}}$ estimation and $\propto$ \\
\hline & Pore pressure $P_{\mathrm{p}}$ & $\begin{array}{l}\text { (Not measured in this well) } \\
\text { Used in } \sigma_{h} \text { and } \sigma_{H} \text {, Shear and Tensile Failure Pressures }\end{array}$ \\
\hline & Image logs & $\begin{array}{l}\text { (Not taken in this well) } \\
\text { In situ stress directions }\end{array}$ \\
\hline \multirow[t]{8}{*}{ Drilling and mud data } & Hole size & $P_{\mathrm{p}}$ (Using Zamora's correlation) \\
\hline & Penetration rate ROP & \\
\hline & Weight on bit WOB & \\
\hline & Rotary speed RPM & \\
\hline & Flow rate GPM (or annular velocity) & \\
\hline & Plastic viscosity PV & \\
\hline & Yield point YP & \\
\hline & Mud weight MW & Evaluation of $P_{p}, \sigma_{r r}$ and for real MW display (in mud window) \\
\hline \multirow[t]{4}{*}{ Core data } & Porosity $\emptyset$ & Calibration of $\log$ data \\
\hline & Young's modulus $E_{\mathrm{s}}$ & \\
\hline & Poisson's ratio $v$ & \\
\hline & Uniaxial compressive strength $(U C S$ ) & \\
\hline Cuttings analysis data & Graphical well log & Lithology, etc., indications \\
\hline Formation integrity test data & Leak-off-test (LOT) & $\begin{array}{l}\text { Calibrating estimated } \sigma_{h} \text { by adjusting the tectonic strain coef- } \\
\text { ficients, } \varepsilon_{x} \text { and } \varepsilon_{y}\end{array}$ \\
\hline
\end{tabular}




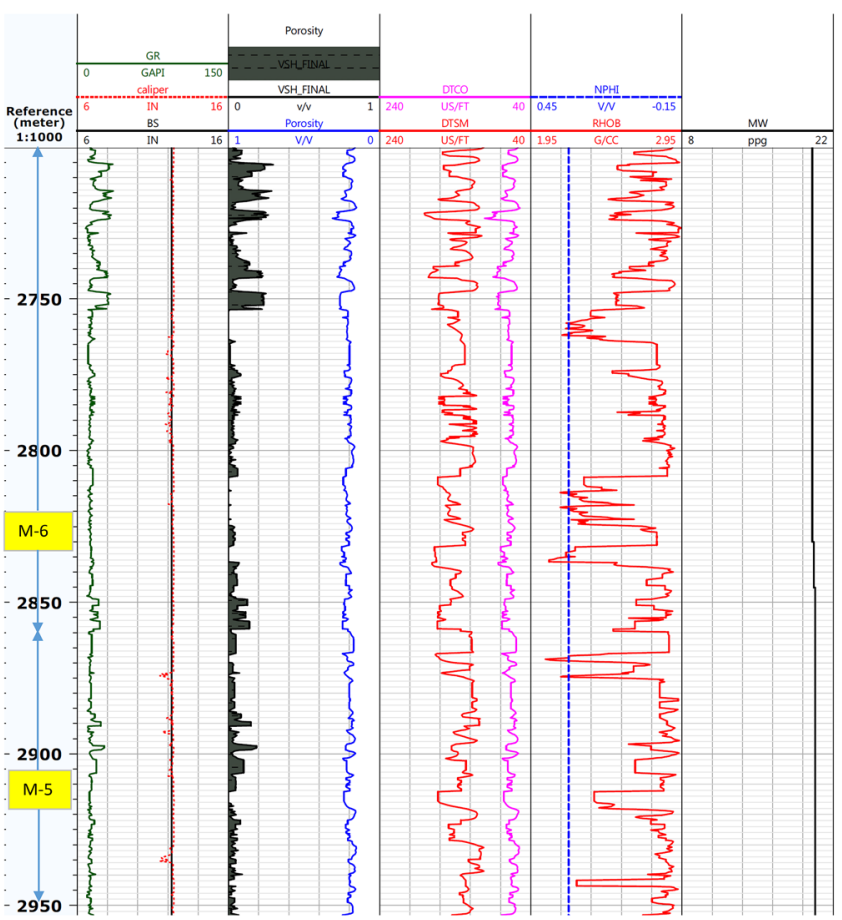

(a)

Fig. 7 a Interpreted petrophysical data and mud weight required for MEM construction in well Z26 (2700-2950 m). The depth intervals of the members of Gachsaran formation have been indicated. b Inter-

Table 3 Core laboratory results (Gachsaran formation)

\begin{tabular}{llll}
\hline Depth $(\mathrm{m})$ & Poisson's ratio & $\begin{array}{l}\text { Young's modu- } \\
\text { lus }(\mathrm{GPa})\end{array}$ & UCS (KPa) \\
\hline 3095.235 & 0.35 & 25 & 65,110 \\
3095.36 & 0.29 & 30 & 76,800 \\
3193.315 & - & 15.97 & 44,000 \\
\hline
\end{tabular}

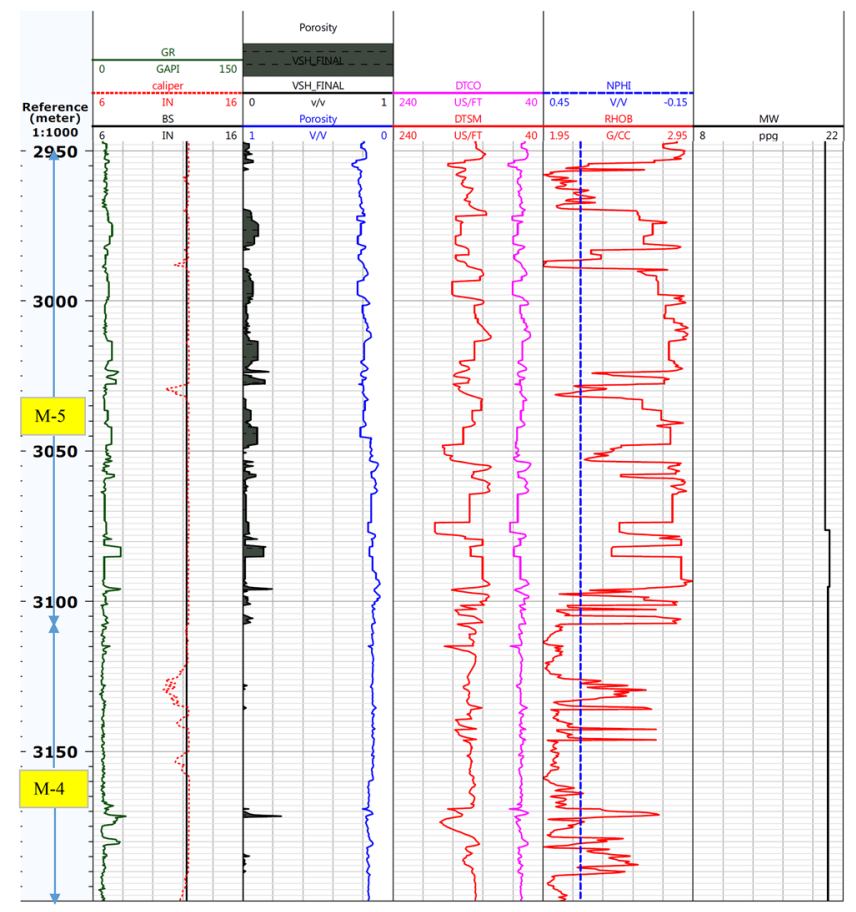

(b)

preted petrophysical data and mud weight required for MEM construction in well Z26 (2950-3200 m)

the maximum horizontal stress of N15E (15 degrees from North).

At some intervals, there were erroneous wireline well log data (e.g., due to malfunction of the centralizers at some intervals) which were filtered. These data were detected using the below detailed observations and replaced by average data of the overlying and underlying readings.

Table 4 Drilling and mud data corresponding to Gachsaran formation (in Kupal field) at some main depths

\begin{tabular}{|c|c|c|c|c|c|c|c|}
\hline Depth (m) & $\begin{array}{l}\text { Average rate of pen- } \\
\text { etration, ROP }(\mathrm{m} / \mathrm{h})\end{array}$ & $\begin{array}{l}\text { Average weight on } \\
\text { bit, WOB (K-Ib) }\end{array}$ & $\begin{array}{l}\text { Revolutions per } \\
\text { minute, RPM }\end{array}$ & $\begin{array}{l}\text { Mud circulation } \\
\text { rate, } \mathrm{Q}(\mathrm{GPM})\end{array}$ & $\begin{array}{l}\text { Yield point, YP } \\
\left(\mathrm{Ibf} / 100 \mathrm{ft}^{2}\right)\end{array}$ & $\begin{array}{l}\text { Plastic viscos- } \\
\text { ity, PV (cp) }\end{array}$ & $\begin{array}{l}\text { Mud } \\
\text { weight } \\
\text { (ppg) }\end{array}$ \\
\hline 2670 & 0.4 & 16 & 75 & 530 & 26 & 88 & 20.05 \\
\hline 2844 & 1.3 & 22 & 170 & 520 & 26 & 84 & 20.32 \\
\hline 2900 & 1.5 & 20 & 170 & 490 & 26 & 81 & 20.32 \\
\hline 2950 & 1.92 & 22 & 170 & 490 & 26 & 78 & 20.32 \\
\hline 3012 & 1.94 & 22.5 & 175 & 49 & 26 & 78 & 20.32 \\
\hline 3076 & 1.94 & 20 & 170 & 480 & 27 & 79 & 20.32 \\
\hline 3095 & 1.96 & 25 & 185 & 500 & 25 & 115 & 20.72 \\
\hline 3172 & 2.5 & 30 & 170 & 480 & 24 & 100 & 20.59 \\
\hline
\end{tabular}


Table 5 The results of graphical well log (obtained from geologist's cuttings analysis) of well Z26 (from top to bottom). It includes Gachsaran formation including its seven member/layers

\begin{tabular}{|c|c|c|c|c|}
\hline & Location & Lithology & Issues & Top MD (m) \\
\hline Aghajari & Covered by 18 5/8-in. CSG & Sandstone + marl & None & Surface \\
\hline Mishan & Covered by 13 1/8-in. CSG & Marl+limestone & Minor losses (possible) (NA in this paper). & 2367 \\
\hline Member-7 & 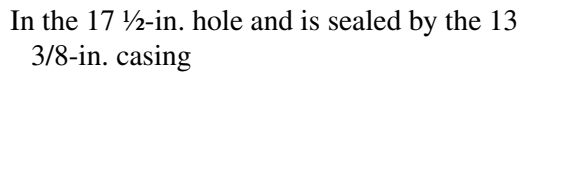 & $\begin{array}{l}\text { Marl + anhy- } \\
\text { drite + gyp- } \\
\text { sum + thin } \\
\text { limestone layers }\end{array}$ & $\begin{array}{l}\text { It is low-pressured, and no drilling issues are } \\
\text { usually reported in this member } \\
\text { Note: It is part of the } 171 / 2-\text {-in. hole, but as it } \\
\text { is a member of Gachsaran formation, it is } \\
\text { discussed here. }\end{array}$ & 2542 \\
\hline Member-6 & $\begin{array}{l}\text { This is the upper G. member in } 121 / 4-i n \text {. hole. } \\
\text { Its top is located just } 1-\mathrm{m} \text { below the } 13 \text { 3/8- } \\
\text { in. casing shoe }\end{array}$ & Red marl + anhydrite & Bit balling and pipe stuck possibility & 2666 \\
\hline Member-5 & Below member 6 & Limestone + marl & $\begin{array}{l}\text { Mud loss (not reported in this well) } \\
\text { Kick flow occurred at } 3076 \mathrm{~m} \\
\text { Tight hole and bit balling (occurred due to } \\
\text { their sticky marl) }\end{array}$ & 2867 \\
\hline Member-4 & Below member 5 & $\begin{array}{l}\text { Thick salt lay- } \\
\text { ers }+ \text { anhy- } \\
\text { drite }+ \text { marl }+ \text { (thin } \\
\text { limestone layers) }\end{array}$ & $\begin{array}{l}\text { Mud loss was reported } \\
\text { Kick flow possibility due to increase in pore } \\
\text { pressure abnormality (this issue was not } \\
\text { reported in this well) } \\
\text { Pipe stuck possibility } \\
\text { Washout possibility due to dissolution of salts } \\
\text { (if the mud is not saturated with salt) } \\
\text { Note: Usually, in this member, we have great } \\
\text { salt creeping because of much salt and great } \\
\text { pore pressure. Thus, to prevent problems } \\
\text { from these two, we increase MW }\end{array}$ & 3116 \\
\hline $\begin{array}{l}\text { Member-3 } \\
\text { Member-2 }\end{array}$ & \multicolumn{4}{|c|}{$\begin{array}{l}\text { Members } 3 \text { and } 2 \text { are salt-containing, but were absent in this well (which indicates the well location is almost located near the } \\
\text { crest of the field). When the well is located near the crest, salt creeps or slips away to the flanks (responsible for some WBS } \\
\text { issues) } \\
\text { Note: Under member } 4 \text {, it is very critical to check in detail (in centimeters) what is below. If salt was detected, it is member } 3 \text {. If } \\
\text { anhydrite is detected, it is member-1 }\end{array}$} \\
\hline Member-1 & It is the cap rock & Mainly anhydrite & $\begin{array}{l}\text { The shoe of } 95 / 8 \text {-in. casing should be located } \\
\text { near the bottom depth of this member }\end{array}$ & 3302.5 \\
\hline Asmari & Reservoir & Limestone & & 3310 \\
\hline
\end{tabular}

Table 6 Mud loss occurrences in well Z26 of Kupal field (used for calibration of the $\sigma_{h}$ estimations by MEM). These specified depths can be indicated for calibration of the minimum horizontal stress

\begin{tabular}{lllll}
\hline Depth (m) & Formation & $\begin{array}{l}\text { Mud weight, } \\
\text { MW (ppg) }\end{array}$ & PH of mud & $\begin{array}{l}\text { Mud loss } \\
\text { volume } \\
\text { (bbl) }\end{array}$ \\
\hline $3082-3095$ & G., m-5 & 20.72 & 9.8 & 25 \\
$3110-3173$ & G., m-4 & 20.58 & 9.5 & 90 \\
$3173-3185$ & G., m-4 & 20.58 & 9.5 & 25 \\
$3194-3234$ & G., m-4 & 20.58 & 9.2 & 100 \\
\hline
\end{tabular}

1. The data with extremely low Young's modulus $(E)$, Poisson's ratio $(v)$ and uniaxial compressive strength (UCS).

2. The data that resulted in tensile failure mud weight lower than shear failure mud weight.

\section{MEM development workflow}

Figure 9 and Table 8 show the workflow of construction of the MEM and determination of the mud weight windows. The process involves estimation of rock elastic moduli and strength properties as well as the pore pressure and in situ

Table 7 Kick flow occurrence data (in member-5 of Gachsaran formation in well Z26)

\begin{tabular}{lllllll}
\hline Depth (m) & Formation & $\mathrm{Ca}^{2+}(\mathrm{ppm})$ & Mud weight, MW (ppg) & $\begin{array}{l}\text { Shut-in casing pressure, } \\
\text { SICP (psi) }\end{array}$ & $\begin{array}{l}\text { Shut-in drill pipe pres- } \\
\text { sure, SIDPP (psi) }\end{array}$ & $\begin{array}{l}\text { Evaluated pore pressure } \\
(\mathrm{psi})\end{array}$ \\
\hline 3076 & G., m-5 & \multirow{2}{*}{140} & $\begin{array}{l}\text { Pre-Kick MW: } 20.32 \\
\text { Kill MW: 20.58 }\end{array}$ & 300 & 140 & 10,805 \\
\hline
\end{tabular}

The shut-in casing pressure, SICP, and shut-in drill pipe pressure, SIDPP, were recorded. The real pore pressure magnitude has been evaluated by adding SIDPP to the old mud column pressure. This will be used to calibrate the pore pressure estimations 


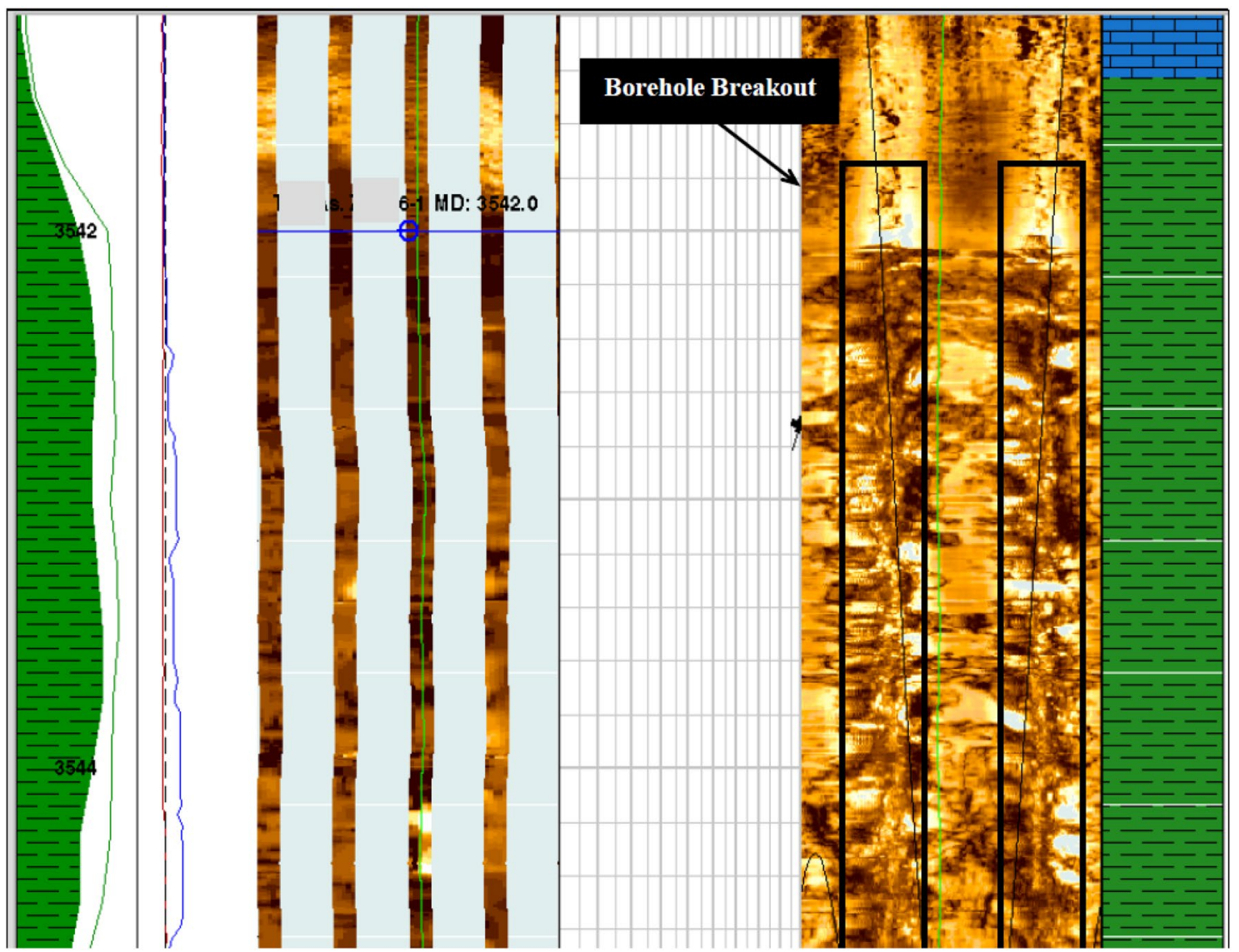

Fig. 8 An example breakout indicating the direction of minimum horizontal stress of N75W

stresses. This is considered a pioneer work of MEM development for such a complex lithology formation (consisting of anhydrite, gypsum, marl and limestone) which included finding the equations best-matching with core data and field observations. The MEM workflow is discussed in the following subsections.

\section{Rock moduli and strength}

The dynamic Young's modulus $E_{\mathrm{d}}(\mathrm{GPa})$ is estimated using (Fjaer et al. 2008):

$E_{\mathrm{d}}=10^{6}\left[\frac{\rho_{\mathrm{b}}}{\Delta t_{\mathrm{s}}^{2}}\right]\left[\frac{3 \Delta t_{\mathrm{s}}^{2}-4 \Delta t_{\mathrm{c}}^{2}}{\Delta t_{\mathrm{s}}^{2}-\Delta t_{\mathrm{c}}^{2}}\right]$

where $\rho_{\mathrm{b}}$ is the bulk density $\left(\mathrm{g} / \mathrm{cm}^{3}\right) ; \Delta t_{\mathrm{c}}$ is the compressional wave slowness $(\mu \mathrm{s} / \mathrm{m}) ; \Delta t_{\mathrm{s}}$ is the shear wave slowness $(\mu \mathrm{s} / \mathrm{m})$.

Based on van Lama and Vutukuri (1978), Barton (2006) and Holt (2013), the static moduli differ from the dynamic moduli. This is because the dynamic measurements are made in a certain (seismic/sonic/ultrasonic) frequency band, strain and stress amplitudes, whereas static moduli represent behavior at very low frequency band, $0.01 \mathrm{1} / \mathrm{s}$ or lower, and large amplitudes (Holt 2013). Based on Plona and Cook (1995) and TerraTek Inc. (1998), the dynamic Young's modulus is often 2-3 times that of the static one. In this paper, for better matching of the static modulus with the core laboratory results, the dynamic Young's modulus $E_{\mathrm{d}}$ is converted to the static one $E_{\mathrm{s}}$ using the following equation (which was modified from Wang 2000 or Plona and Cook 1995 to match with the core data):

$E_{\mathrm{s}}=0.46 E_{\mathrm{d}}$

The results of $E_{\mathrm{s}}$ were calibrated using the core test data at three different depths (see Table 3).

Next, the dynamic Poisson's ratio $v_{\mathrm{d}}$ is estimated using shear and compressional slowness times, $\Delta t_{\mathrm{s}}$ and $\Delta t_{\mathrm{c}}$ (Fjaer et al. 2008):

$v_{\mathrm{d}}=\frac{1}{2} \frac{\left(\frac{\Delta t_{\mathrm{s}}}{\Delta t_{\mathrm{c}}}\right)^{2}-2}{\left[\left(\frac{\Delta t_{\mathrm{s}}}{\Delta t_{\mathrm{c}}}\right)^{2}-1\right]}=\frac{1}{2} \frac{\Delta t_{\mathrm{s}}^{2}-2 \Delta t_{\mathrm{c}}^{2}}{\left[\Delta t_{\mathrm{s}}^{2}-\Delta t_{\mathrm{c}}^{2}\right]}$ 
Fig. 9 Constructing the mechanical earth model (MEM) for WBS providing induced stresses and safe mud window

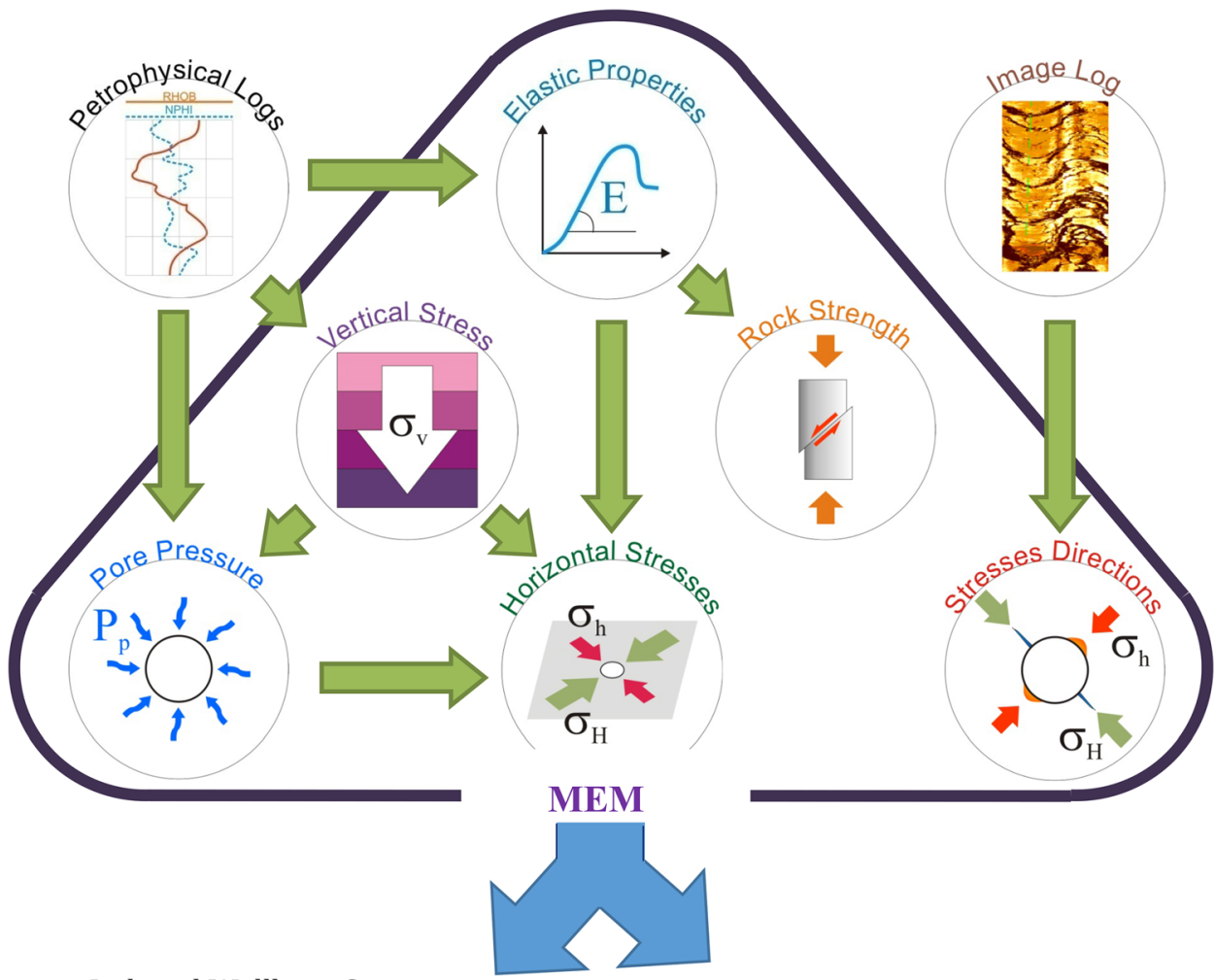

Induced Wellbore Stresses

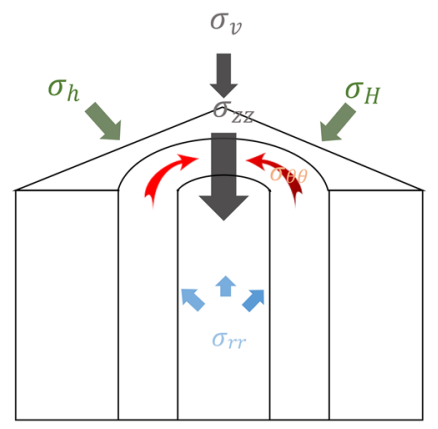

Safe Mud Window

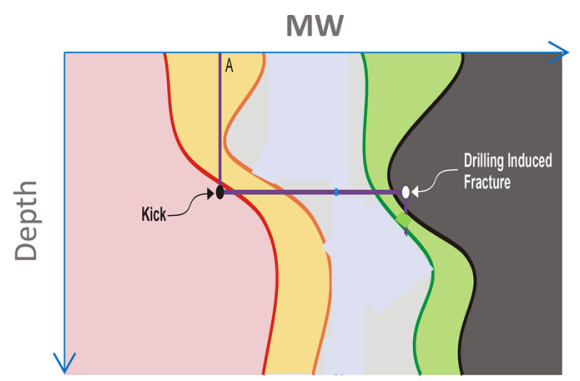

Assuming an elastic medium, based on Larsen et al. (2000), the non-elastic shear deformation coefficients vanish and thus the dynamic and static Poisson's ratios are equal $\left(v_{\mathrm{s}}=v_{\mathrm{d}}\right)$.

Different UCS correlations for the uniaxial compressive strength (UCS) listed in Chang et al. (2006) were checked. In this work, Militzer and Stoll's correlation (1973) was found as the best-matching correlation with the core data:

$\mathrm{UCS}=\frac{1}{145}\left(\frac{7682}{\Delta t_{\mathrm{c}}}\right)^{1.82}$

This equation was calibrated against core test results (see Table 3).

The tensile strength of essentially all rocks is quite low, on the order of just a few MPa (Lockner and Byerlee
1995). Therefore, in this work, it is considered $1 / 10$ of the UCS (Jaeger et al. 2007).

Next, as the internal friction angle $\varphi$ is required for determination of the shear failure pressure/equivalent mud weight, Plumb correlation (Plumb 1994) is commonly used to estimate it:

$\varphi=26.5-37.4\left(1-\emptyset-V_{\text {shale }}\right)+62.1\left(1-\emptyset-V_{\text {shale }}\right)^{2}$

In this correlation, $V_{\text {shale }}$ (shale volume) is found using the gamma log measurements $\left(V_{\text {shale }}=\frac{\mathrm{GR}-\mathrm{GR}_{\min }}{\mathrm{GR}_{\max }-\mathrm{GR}_{\min }}\right) ; \emptyset$ is neutron porosity which is estimated by the neutron $\log$ porosity (NPHI). In case NPHI is not available, it can be estimated using its correlation with UCS considering the lithology (Chang et al. 2006). 
Table 8 Steps and parameters in the procedure for constructing the MEM

\begin{tabular}{lll}
\hline Step & Parameter & What data are required? \\
\hline 1. Rock moduli and strength & Young's modulus $E$ & $\Delta t_{\mathrm{c}}, \Delta t_{\mathrm{s}}$ \\
& Poison's ratio $v$ & $\rho_{\mathrm{b}}$ \\
& Uniaxial compressive strength UCS & (Considering lithology) \\
2. Internal friction angle $\varphi$ & $\varphi$ & $\emptyset$ (or NPHI) \\
3. Pore pressure $P_{\mathrm{p}}$ & & $V_{\text {shale }}$ \\
& $P_{\mathrm{p}}$ & Hole size \\
& & Drilling data (ROP, WOB, \\
& & RPM and GPM) \\
& & Mud data (MW, YP, PV) \\
4. In situ stresses & Overburden stress $\sigma_{v}$ & $\rho_{b}$ and depth (TVD) \\
& Minimum horizontal stress $\sigma_{h}$ & $\sigma_{v}$ and $P_{\mathrm{p}}$ \\
& Maximum horizontal stress $\sigma_{H}$ & $E$ and $v$ \\
& & $\alpha$ \\
& & $\varepsilon_{x}$ and $\varepsilon_{y}$ \\
& & LOT data (for calibration of $\sigma_{h}$ ) \\
& & MW and TVD \\
5. Induced wellbore stresses & Radial stress $\sigma_{r r}$ & $\sigma_{h}, \sigma_{H}$ and $\sigma_{r r}$ \\
& Tangential stress $\sigma_{\theta \theta}$ & $\sigma_{h}, \sigma_{H}, \sigma_{v}$ \\
& Axial stress $\sigma_{z z}$ & and $v$ \\
& & $P_{p}$ and TVD \\
& & $\sigma_{h}, \sigma_{H}, P_{\mathrm{p}}$ \\
& Pore pressure/gradient & $\sigma_{h}$ and TVD \\
& Shear failure pressure/gradient & $\sigma_{h}, \sigma_{H}$ \\
& & $P_{p}$ and TVD \\
& Mud lost pressure/mud gradient &
\end{tabular}

Based on the estimation for the Gachsaran formation, in this work, the angle $\varphi$ ranges from 21 to 43 degrees, and its average magnitude is 23 degrees.

The ranges of the estimated rock moduli and strength are given in Table 9.

\section{Pore pressure}

Measurement of the pore pressure is typically conducted by repeat formation tester (RFT), modular dynamics testing (MDT), well test analysis, logging while drilling sensor, etc. However, as the pore pressure of Gachsaran formation is excessively abnormal and its permeability is so low at some intervals (with high percentage of anhydrite/

Table 9 The ranges of estimated static elastic moduli (including the bulk modulus, $K_{b}$ and shear modulus $G$ ) and rock strength of Gachsaran formation in Kupal field (using MEM results of well Z26)

\begin{tabular}{lccc}
\hline & Min & Mean & Max \\
\hline$E(\mathrm{GPa})$ & 8.07 & 16.51 & 30.81 \\
$K(\mathrm{GPa})$ & 5.57 & 15.77 & 30.52 \\
$G(\mathrm{GPa})$ & 2.89 & 6.26 & 11.89 \\
$\nu$ & 0.23 & 0.33 & 0.42 \\
$\mathrm{UCS}(\mathrm{MPa})$ & 16.42 & 41.1 & 81.6 \\
\hline
\end{tabular}

gypsum or salt), direct measurement was not practically possible. Therefore, in this work, it was indirectly estimated using correlations, which was calibrated using real pore pressure value(s) during kick flows (also indicated by calcium ion increase in the mud). Generally, some pore pressure correlation methods include the drilling exponent, seismic data (Dugan and Flemings 1998), sonic log using Eaton's or Bowers method (Bowers 1994; Zhang 2011), or resistivity log (Zhang 2011; Mouchet and Mitchell 1989). These methods are based on the fact that the porosity of shale is expected to decrease monotonically as the vertical effective stress $\left(\sigma v-\alpha P_{\mathrm{p}}\right)$ increases, which are susceptible to some complexities (Zoback 2010). Alternative methods are the modified-drilling exponent methods (Rehm and McClendon 1971; Zamora 1972; Bourgoyne et al. 1986). In this work, Zamora's model showed bestmatching results (with field observations data) and was used for estimation of pore pressure.

As the pore pressures derived from $\log s$ and other sources are not accurate, calibration of the pore pressure estimations is essential (Aadnoy and Looyeh 2010). Therefore, in this work, the kick flow data were used for calibration of the estimated pore pressures. For this purpose, at the depth of $3076 \mathrm{~m}$, Table 7), the measured surface shut-in drill pipe pressure (SIDPP) was added to the old 
mud pressure to find the real pore pressure, which is used to calibrate the estimations.

Modified $D$-exponent method (Zamora 1972):

In this method, first, the $d$-exponent, $d_{\exp }$ is found as follows:

$d_{\text {exp }}=\frac{\log \left\{\frac{\text { ROP }}{60 \text { RPM }}\right\}}{\log \left\{\frac{12 \mathrm{WOB}}{1000 d_{\mathrm{B}}}\right\}}$

Next, the modified $d$-exponent $d_{\text {mod }}$ is found:

$d_{\text {mod }}=\frac{\rho_{\mathrm{n}}}{\rho_{\mathrm{e}}} d_{\exp }$

In the above equations, ROP is the rate of penetration $(\mathrm{ft} / \mathrm{h})$; RPM is the revolutions per minute, WOB is the weight on the bit (k.Ibf); $d_{\mathrm{B}}$ is the bit size/diameter (in); $\rho_{\mathrm{n}}$ is the normal pore pressure in the region (ppg); $\rho_{\mathrm{e}}$ is the equivalent circulating density, or ECD (ppg).

Next, the normal trend-line of modified $d$-exponent $\left(d_{\text {mod,n }}\right)$ can be established using the normal trend-line. However, as all the members of Gachsaran formation are already abnormally over-pressured, we cannot use the available data to plot the normal trend-line and find $d_{\text {mod,n }}$ curve. Thus, alternatively, Zamora's relation between $d_{\text {mod,n }}$ and $d_{\text {mod, } 0}$ is used (Bourgoyne et al. 1986):

$d_{\text {mod, } \mathrm{n}}=d_{\text {mod, }, 0} \mathrm{e}^{m D}$

where $d_{\text {mod, } 0}$ is the modified $d$-exponent; $D$ is the TVD (ft); and " $m$ " is a constant to be found for each region. Using the data in Table 4 , we evaluated the $d_{\text {mod }}$ value for each data set. Next, in order to evaluate $d_{\text {mod,n }}$, we considered the value of $3.9 \times 10^{-5}$ for " $m$ " in the above equation (considering Bourgoyne et al. 1986) and changed $d_{\text {mod, } 0}$ until matching and calibration with the real pore pressure value at $3076 \mathrm{~m}$ was obtained. The value of 1.26 was found as the best fitting

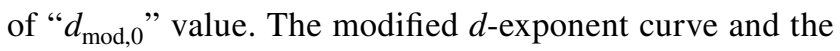
normal trend-line, $d_{\text {mod,n }}$, are plotted in Fig. 10. Based on Table 7, at the depth of $3076 \mathrm{~m}$, kick flow occurred and shutin pressures were obtained for real pore pressure evaluation.

Finally, using Zamora's Eq. (1972), considering the normal pore pressure gradient $\left(\mathrm{PG}_{\mathrm{n}}\right)$ equal to $0.445 \mathrm{psi} / \mathrm{ft}$, the pore pressure gradients $\left(\mathrm{PG}_{\mathrm{p}}\right)$ were found using the following equation:

$\mathrm{PG}_{\mathrm{p}}=\frac{d_{\text {mod,n }}}{d_{\text {mod }}} \mathrm{PG}_{\mathrm{n}}$

As Table 10 shows, the abnormality of this formation in pore pressure is excessively high (ranging from 0.96 to 1.07 , which is comparable with $1 \mathrm{psi} / \mathrm{ft}$, i.e., the overburden pressure gradient in Gulf of Mexico). This abnormality is mainly

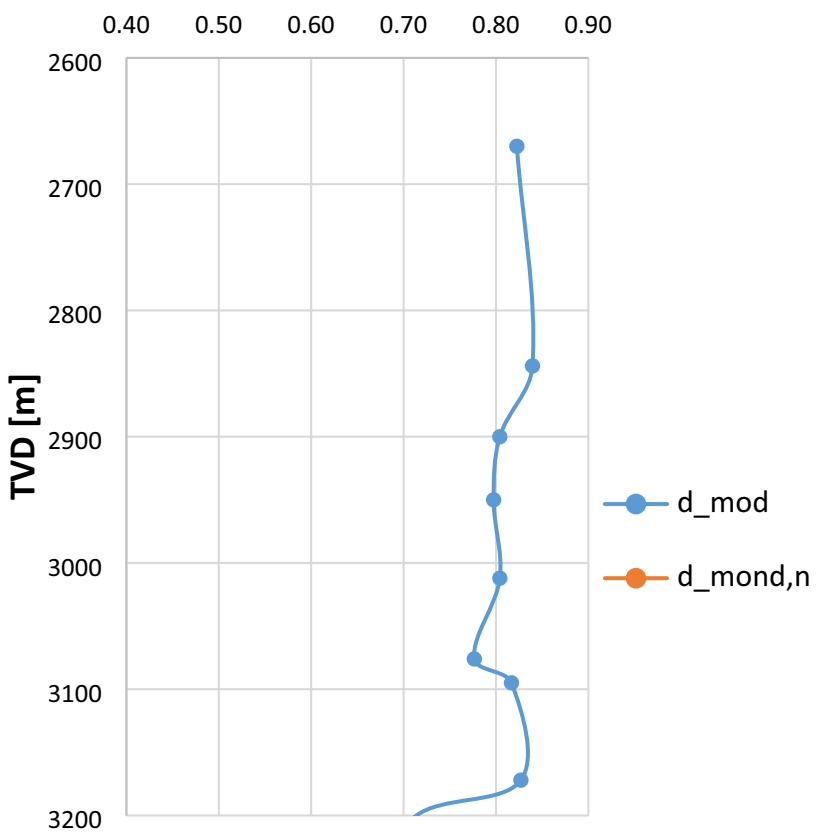

Fig. 10 Normal trend-line of the modified $d$-exponent (following fitting of Zamora's model for Gachsaran formation) versus the modified $d$-exponent values

attributed to the conversion of gypsum to anhydrite in a closed basin during geologic time.

\section{In situ stresses}

The overburden stress $\sigma_{v}$ is required to evaluate the horizontal stresses. Using the density log readings $\left(\rho_{b}\right)$, we can estimate the overburden stress as follows:

$\sigma_{v}=\int_{0}^{z} \rho_{b}(z) g \mathrm{~d} z$

The bulk density for the reservoir section has been evaluated by the well logs; however, for the sections where density $\log$ data are unavailable, the seismic velocity $v p$ can be used for the estimation of overburden stress (Mavko et al. 1995). In this paper, for the non-logged interval (above $2700 \mathrm{~m}$ ), the overburden pressure gradient of 1.13-1.15 psi/ft (which has been estimated for the Middle Eastern fields in the region) was used.

In a tectonically active basin, the practical way to estimate minimum $\left(\sigma_{h}\right)$ and maximum $\left(\sigma_{H}\right)$ horizontal stresses is by using the tectonic stress terms. The poro-elastic relations are commonly used to estimate horizontal stresses (Blanton and Olson 1997): 
Table 10 Using Zamora's $d$-exponent method to estimate pore pressure gradients of Gachsaran formation

\begin{tabular}{|c|c|c|c|c|c|c|c|c|c|c|}
\hline Depth (m) & $\mathrm{ROP}(\mathrm{m} / \mathrm{h})$ & WOB (K-Ib) & RPM & EMW (ppg) & ECD (ppg) & $d$-exp & $d \_$mod & $d \_$mod,n & $\mathrm{PG}_{\mathrm{p}}(\mathrm{psi} / \mathrm{ft})$ & PP (psi) \\
\hline 2670 & 0.4 & 16 & 75 & 20.05 & 20.38 & 1.96 & 0.82 & 1.77 & 0.96 & 8403 \\
\hline 2844 & 1.3 & 22 & 170 & 20.32 & 20.67 & 2.03 & 0.84 & 1.81 & 0.96 & 8967 \\
\hline 2900 & 1.5 & 20 & 170 & 20.32 & 20.67 & 1.94 & 0.80 & 1.83 & 1.01 & 9616 \\
\hline 2950 & 1.92 & 22 & 170 & 20.32 & 20.67 & 1.93 & 0.80 & 1.84 & 1.03 & 9926 \\
\hline 3012 & 1.94 & 22.5 & 175 & 20.32 & 20.67 & 1.94 & 0.80 & 1.85 & 1.03 & 10,130 \\
\hline 3076 & 1.94 & 20 & 170 & 20.32 & 20.68 & 1.88 & 0.78 & 1.87 & 1.07 & 10,802 \\
\hline 3095 & 1.96 & 25 & 185 & 20.72 & 21.06 & 2.01 & 0.82 & 1.87 & 1.02 & 10,358 \\
\hline 3172 & 2.5 & 30 & 170 & 20.59 & 20.91 & 2.02 & 0.83 & 1.89 & 1.02 & 10,589 \\
\hline
\end{tabular}

Compare the estimated value of 10,802 psi at the depth $3076 \mathrm{~m}$ with the real pore pressure of 10,805 psi (Table 7)

$\sigma_{h}=\frac{v}{1-v}\left(\sigma_{V}-\alpha P_{\mathrm{p}}\right)+\alpha P_{\mathrm{p}}+\sigma_{\text {tect } h}$

$\sigma_{H}=\frac{v}{1-v}\left(\sigma_{V}-\alpha P_{\mathrm{p}}\right)+\alpha P_{\mathrm{p}}+\sigma_{\text {tect } H}$

Here, $v$ is the Poisson's ratio; $P_{\mathrm{p}}$ is the pore pressure; $\sigma_{\text {tect }}$ is the tectonic stress; and $\alpha$ is Biot's coefficient (with the value of 0.7 in this study, considering Zoback 2010).

Including the tectonic terms, it enables shifting the minimum horizontal stress to match the real measured data (typically leak-off-test data). This is called the strain-corrected method (Blanton and Olson 1997).

Replacing the equivalent equations for the tectonic stresses in the above equations (including the tectonic strain coefficients in the direction of minimum horizontal stress, $\varepsilon_{x}$, and in the direction of maximum horizontal stress, $\varepsilon_{y}$ ) gives (Blanton and Olson 1997):

$\sigma_{h}=\frac{v}{1-v}\left(\sigma_{V}-\alpha P_{\mathrm{p}}\right)+\alpha P_{\mathrm{p}}+\frac{E \varepsilon_{x}}{1-v^{2}}+\frac{v E \varepsilon_{y}}{1-v^{2}}$

$\sigma_{H}=\frac{v}{1-v}\left(\sigma_{V}-\alpha P_{\mathrm{p}}\right)+\alpha P_{\mathrm{p}}+\frac{E \varepsilon_{y}}{1-v^{2}}+\frac{\nu E \varepsilon_{x}}{1-v^{2}}$

Using the leak-off-test (LOT), mini-frac test results (or in this study, the mud pressure at the depths where mud loss occurred), we can calibrate the estimated $\sigma_{h}$ values (inferred from Zoback 2010), which is used to adjust $\varepsilon_{x}$ and $\varepsilon_{y}$. This method will inevitably calibrate the values of $\sigma_{H}$. It is noted that there is another method for correlating between $\sigma_{h}$ and $\sigma_{H}$ by Sinha et al. (2006) and Sayers et al. (2009)

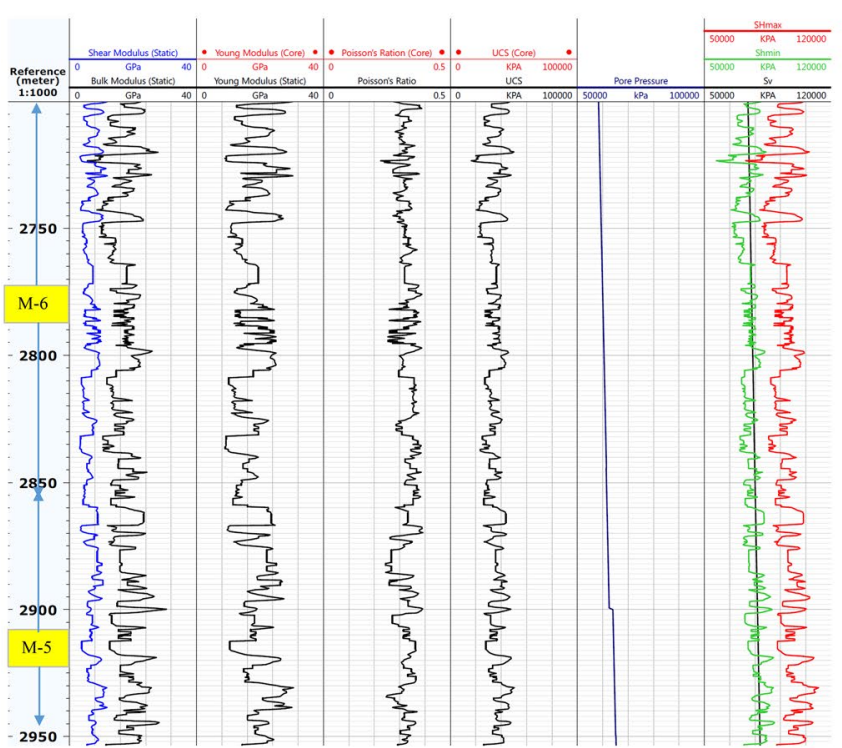

(a)

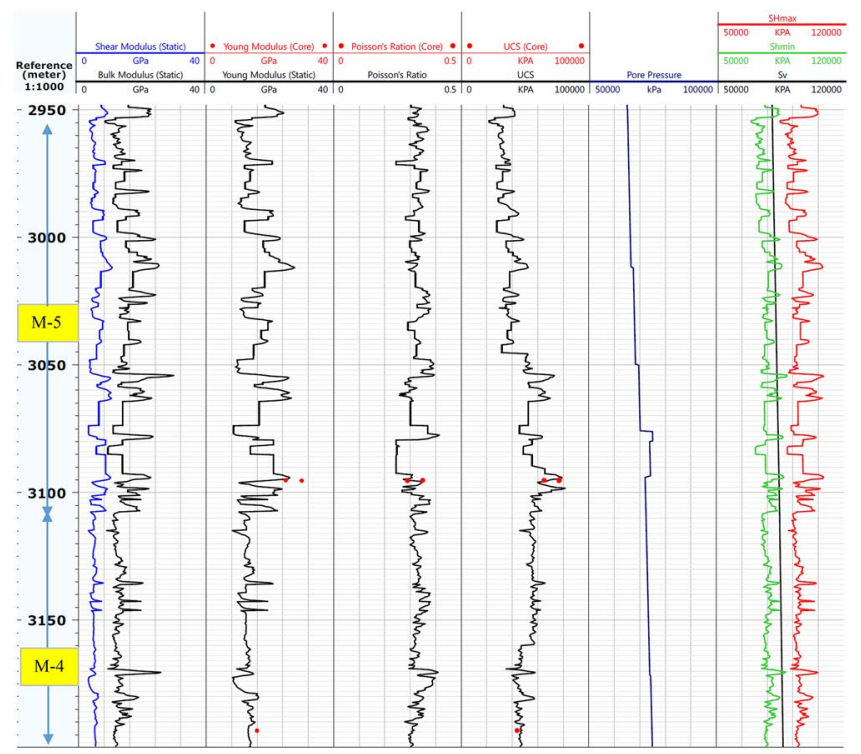

(b)

Fig. 11 a The MEM geomechanical parameters for Gachsaran formation in well Z26 (2700-2950 m). b The MEM geomechanical parameters for well Z26 (2950-3200 m) 
using the vertical and horizontal shear moduli in anisotropic formations.

Finally, following the calibration, the results of the evaluated rock moduli and strength, pore pressure, and in situ stresses can be shown in Fig. 11, as the MEM. The ranges of the in situ stresses of Gachsaran formation of Kupal field are listed in Table 11. Comparing the magnitudes of the stresses in Fig. 11, it is obvious that the stress regime in Gachsaran formation is dominantly strike slip fault (as $\sigma_{H}>\sigma_{v}>\sigma_{h}$ ), whereas at some depths the reverse fault regime (as $\sigma_{H}>\sigma_{h}>\sigma_{v}$ ) is observed.

\section{Drilling-induced stresses}

Kirsch (1898) developed a set of equations for calculating the stresses acting in a (1) thick, (2) homogeneous, isotropic, (3) elastic plate (which can be assumed so when the formation is below half of its compressive strength, Goodman 1989), (4) containing a cylindrical hole, which is subject to effective minimum and maximum far field principal stresses. As well Z26 in this study is vertical, no stress transformations are required (Bradley 1979), and the three principal stresses are the effective radial stress $\left(\sigma_{r r}\right)$, the effective tangential/circumferential stress $\left(\sigma_{\theta \theta}\right)$ and the effective axial stress $\left(\sigma_{z z}\right)$. We can estimate these induced stresses at the wellbore wall as follows (Jaeger and Cook 1979):

$\sigma_{r r}=P_{\mathrm{w}}-\left(\alpha P_{\mathrm{p}}\right)$

$\sigma_{\theta \theta}=\left(\sigma_{H}+\sigma_{h}\right)-P_{\mathrm{w}}-\left(\alpha P_{\mathrm{p}}\right)-2\left(\sigma_{H}-\sigma_{h}\right) \operatorname{Cos}(2 \theta)$

$\sigma_{z z}=\sigma_{v}-\left(\alpha P_{\mathrm{p}}\right)-2 v\left(\sigma_{H}-\sigma_{h}\right) \operatorname{Cos}(2 \theta)$

where $P_{\mathrm{w}}$ is the wellbore pressure evaluated by the mud weight; $\alpha$ is the Biot's coefficient which is considered equal to 0.7 in this work; $\theta$ is the angle from the direction of the $\sigma_{H}$.

The greatest possibility for tensile failure at the wellbore wall is in the direction of $\sigma_{H}(\theta=0)$, where the Kirsch's equations are simplified to:

$\sigma_{r r}=P_{\mathrm{w}}-\left(\alpha P_{\mathrm{p}}\right)$

Table 11 The ranges of in situ stresses of Gachsaran formation (Kupal field) using the MEM results of well Z26

\begin{tabular}{lllr}
\hline & Min & Mean & \multicolumn{1}{c}{ Max } \\
\hline$\sigma_{v}(\mathrm{MPa})$ & 74.05 & 80.55 & 86.64 \\
$\sigma_{h}(\mathrm{MPa})$ & 56.64 & 76.77 & 89.33 \\
$\sigma_{H}(\mathrm{MPa})$ & 72.76 & 95.40 & 113.12 \\
\hline
\end{tabular}

$\sigma_{\theta \theta}=3 \sigma_{h}-\sigma_{H}-P_{\mathrm{w}}-\left(\alpha P_{\mathrm{p}}\right)$

$\sigma_{z z}=\sigma_{v}-\left(\alpha P_{\mathrm{p}}\right)-2 v\left(\sigma_{H}-\sigma_{h}\right)$

The greatest possibility for shear failure (breakout) at the wellbore wall is at $\theta=90$, where the Kirsch's equations are simplified to:

$\sigma_{r r}=P_{\mathrm{w}}-\left(\alpha P_{\mathrm{p}}\right)$

$\sigma_{\theta \theta}=3 \sigma_{H}-\sigma_{h}-P_{\mathrm{w}}-\left(\alpha P_{\mathrm{p}}\right)$

$\sigma_{z z}=\sigma_{v}-\left(\alpha P_{\mathrm{p}}\right)+2 v\left(\sigma_{H}-\sigma_{h}\right)$

The induced stresses calculated for well Z26 are plotted in Fig. 12, and the ranges of induced stresses are provided in Table 12. Table 13 provides the order of the three induced stresses in the direction of minimum horizontal stress (which will be used to determine the potential shear failure) and also the order of the induced stresses in the direction of maximum horizontal stress (which will be considered in determination of the potential tensile failure pressure).

\section{Safe mud weight window}

Construction of safe mud weight window is a really significant part of well planning and operations either in overbalanced drilling, or underbalanced drilling (Guo and Ghalambor 2002). This window is the final result of the 1-D mechanical earth model. It combines the equivalent gradients of pore pressure, shear failure (breakout), mud loss and tensile failure (fracture) in a single figure. The safe mud window consists of a lower and an upper boundaries. The lower boundary is constituted by either the pore pressure or shear failure profile (whichever greater). The upper boundary is constituted by the mud lost profile or the tensile failure profile. The following section explains the steps taken to construct the safe mud weight window.

\section{Pore pressure gradient}

Having estimated the pore pressure using the modified $d$-exponent method, its equivalent mud pressure gradient $\left(\mathrm{PG}_{\mathrm{p}}\right)$ is calculated as:

$\mathrm{PG}_{\mathrm{p}} \geq \frac{P_{\mathrm{p}}}{(9.81 \times \mathrm{TVD})}$

where $P_{\mathrm{p}}$ is the pore pressure in KPa and TVD is true vertical depth in $\mathrm{m}$. 


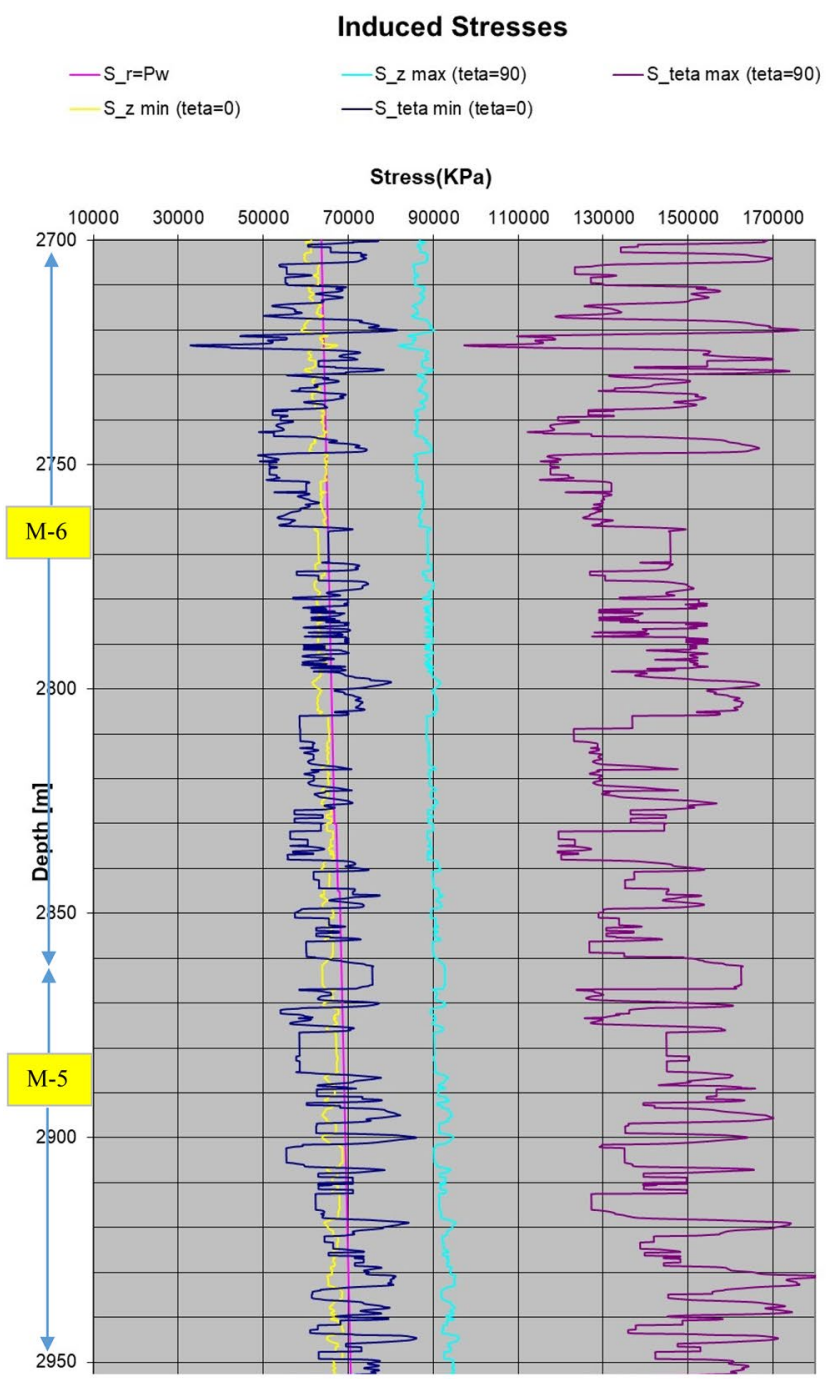

(a)

\section{Induced Stresses}

-S_z max (teta=90)

-S_teta $\min ($ teta $=0)$

-S_teta max (teta=90)

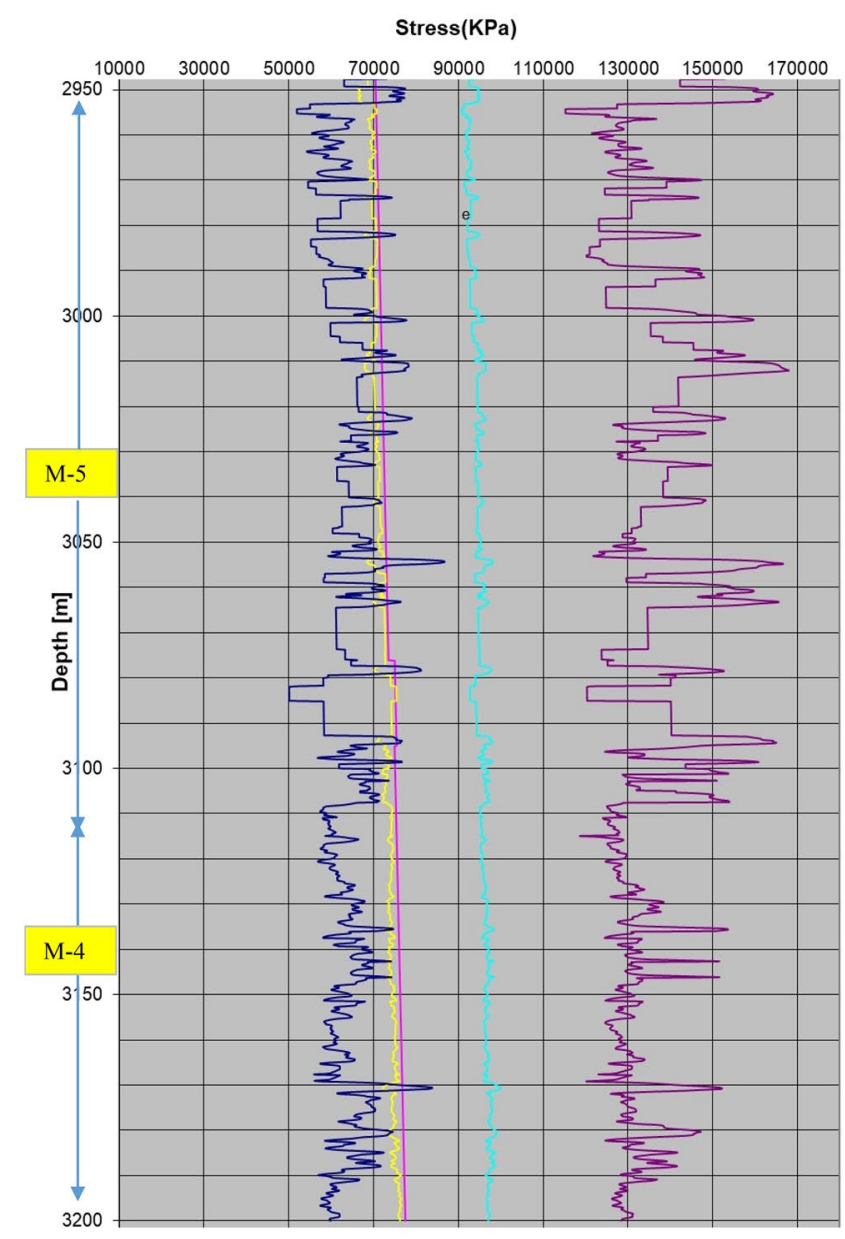

(b)

Fig. 12 a Induced stresses at the wellbore wall (in the direction of $\sigma_{h}$ ) in Gachsaran formation of well Z26 (2700-2950 m). b Induced stresses at the wellbore wall in Gachsaran formation of well Z26 (2950-3200 m)

Table 12 The ranges of induced stresses at the wellbore wall in the direction of minimum horizontal stress $(\theta=90)$ and in the direction of maximum horizontal stress $(\theta=0)$ for Gachsaran formation of Kupal field, using the MEM results of well Z26

\begin{tabular}{|c|c|c|c|}
\hline & Min & Mean & $\operatorname{Max}$ \\
\hline \multicolumn{4}{|c|}{$\theta=90$ (in the direction of $\sigma_{h}$ ) } \\
\hline$\sigma_{\theta \theta}(\mathrm{MPa})$ & 97.4 & 138.88 & 181.12 \\
\hline$\sigma_{z z}(\mathrm{MPa})$ & 81.93 & 92.56 & 99.91 \\
\hline$\sigma_{r r}(\mathrm{MPa})$ & 63.68 & 70.53 & 77.5 \\
\hline \multicolumn{4}{|c|}{$\theta=0$ (in the direction of $\sigma_{H}$ ) } \\
\hline$\sigma_{\theta \theta}(\mathrm{MPa})$ & 32.9 & 64.4 & 86.74 \\
\hline$\sigma_{z z}(\mathrm{MPa})$ & 58.9 & 68.5 & 76.56 \\
\hline$\sigma_{r r}(\mathrm{MPa})$ & 63.7 & 70.5 & 77.5 \\
\hline
\end{tabular}

Table 13 The order of induced wellbore stresses in Gachsaran formation of well Z26 (in the directions of horizontal stresses)

\begin{tabular}{ll}
\hline Direction & Order of induced wellbore stresses \\
\hline Direction of $\sigma_{h}(\theta=90)$ & $\sigma_{\theta \theta}>\sigma_{z z}>\sigma_{r r}$ \\
Direction of $\sigma_{H}(\theta=0)$ & $\begin{array}{c}\sigma_{r r}>\sigma_{z z}>\sigma_{\theta \theta}, \text { or } \sigma_{\theta \theta}>\sigma_{r r}>\sigma_{z z} \\
\text { (at some depths) }\end{array}$ \\
\hline
\end{tabular}

\section{Shear failure pressure gradient}

The drilling-induced shear failure is the compressive shear failure of the wellbore wall, which makes the intersecting conjugate shear planes resulting in pieces of rock spalling off the wellbore wall and its ovalization (Bell and Gough 1979; Meyer 2002). The shear failure criteria considered 
in this work are Mohr-Coulomb (MC), Mogi-Coulomb (MG), and Modified Lade (ML). The pressure causing the shear failure depends on the shear failure mode, which is determined based on the order of induced/near wellbore stresses (Aadnoy and Looyeh 2010). In the case of the studied well, based on the order of the induced stresses in the direction of the minimum horizontal stress $\left(\sigma_{\theta \theta}>\sigma_{z z}>\sigma_{r r}\right)$, the mode of failure is known as widebreakout (Bowes and Procter 1997) and the minimum mud pressure to avoid breakout, $P_{\mathrm{w}, \mathrm{s}}$ is calculated as (Mohr-Coulomb criterion):

$P_{\mathrm{w}, \mathrm{s}} \geq \frac{3 \sigma_{H}-\sigma_{h}-U C S+\alpha P_{\mathrm{p}}(q-1)}{(q+1)}$

where $q=(1+\sin \varphi) /(1-\sin \varphi)$.

The shear failure pressure gradient is:

$\mathrm{PG}_{\mathrm{w}, \mathrm{s}} \geq \frac{\mathrm{PG}_{\mathrm{w}, \mathrm{s}}}{(9.81 \times \mathrm{TVD})}$

\section{Mud loss pressure gradient}

The pressure required for mud loss $\left(P_{\mathrm{w}, \mathrm{l}}\right.$ in $\left.\mathrm{gr} / \mathrm{cc}\right)$ is equal to $\sigma_{h}$ and its corresponding equivalent mud weight $\left(\mathrm{PG}_{\mathrm{w}, \mathrm{l}}\right)$ is calculated as:

$\mathrm{PG}_{\mathrm{w}, \mathrm{l}} \geq \frac{\sigma_{h}}{(9.81 \times \mathrm{TVD})}$

where, $\sigma_{h}$ is in KPa and TVD is in $\mathrm{m}$.

\section{Tensile failure pressure gradient}

This failure is the upper limit of the safe mud weight window. The Fracture initiates when the effective minimum principal stress $\left(\sigma_{3}\right)$ at the wellbore wall (in the direction of $\sigma_{H}$ at $\theta=0$ ) reaches or exceeds formation rock tensile strength, $T_{0}$ (Fjaer et al. 2008). The tensile failure pressure is:

$P_{\mathrm{w}, 1} \geq 3 \sigma_{H}-\sigma_{H}-\alpha P_{p}$

The tensile failure pressure gradient is:
$\mathrm{PG}_{\mathrm{w}, \mathrm{t}} \geq \frac{3 \sigma_{H}-\sigma_{H}-\alpha P_{p}}{(9.81 \times \mathrm{TVD})}$

The order of stresses in well Z26 is either $\left(\sigma_{r r}>\sigma_{z z}>\sigma_{\theta \theta}\right)$ or $\left(\sigma_{\theta \theta}>\sigma_{r r}>\sigma_{z z}\right)$; therefore, either $\sigma_{\theta \theta}$ or $\sigma_{z z}$ is the $\sigma_{3}$. In either mode, the tensile failure pressure $\left(P_{\mathrm{w}, \mathrm{t}}\right)$ is evaluated (as shown in Table 14).

Figure 13 shows the safe mud weight window of Gachsaran formation (in well Z26) using three failure criteria (Mohr-Coulomb, MC; Mogi-Coulomb, MG and Modified Lade, ML). Table 15 shows the ranges of the pore pressure, shear failure, mud loss and tensile failure boundaries. Some differences in the shear failure boundary can be seen between the results of the different failure criteria.

\section{Results and discussion}

Using the geomechanical model and safe mud window developed for Gachsaran formation of well Z-26 (Fig. 13), the field operational challenges are first inferred by considering the safe mud window and field observations of mud loss and kick. Finally, to overcome such hole problems in the future, two innovative drilling systems are proposed as the remedial actions.

\section{Field operational challenges}

In the 2700-2950 m interval of Fig. 13, it is observed that the mud weights are lower than shear failure boundary causing shear failure to occur, which is confirmed by numerous tight holes in this depth interval. Next, we can see that the pore pressure suddenly increases around the depth of $3050 \mathrm{~m}$ and even exceeds the shear failure pressure. Due to the increased abnormality of the pore pressure, it exceeds the mud column pressure a few meters deeper $(3076 \mathrm{~m})$, i.e., kick flow is shown (which was confirmed by the crew's experience). It is also observed that the mud weight reaches the mud loss boundary causing mud losses, which is confirmed by the loss observations at the rig site. Above all, the safe mud weight window is narrow and maintaining drilling mud weights in this window is not practically possible. Therefore, some methods to mitigate this problem should be found.
Table 14 Tensile failure pressures for different tensile failure modes (Simangunsong et al. 2006; Zhang et al. 2006)

\begin{tabular}{|c|c|c|}
\hline Mode & Criteria & Tensile failure pressure $\left(P_{w, t}\right)$ \\
\hline $\begin{array}{l}\text { Mode I: }\left(\sigma_{r r}>\sigma_{z z}>\sigma_{\theta \theta}\right) \\
\text { (Vertical fracture) }\end{array}$ & $\sigma_{\theta \theta}-T_{0} \leq 0$ & $P_{\mathrm{w}, \mathrm{t}} \leq 3 \sigma_{h}-\sigma_{H}-\left(\alpha P_{\mathrm{p}}\right)-T_{0}$ \\
\hline $\begin{array}{l}\text { Mode II: }\left(\sigma_{\theta \theta}>\sigma_{r r}>\sigma_{z z}\right) \\
\text { (Horizontal fracture) }\end{array}$ & $\sigma_{z z}-T_{0} \leq 0$ & $P_{\mathrm{w}, \mathrm{t}} \leq 3 \sigma_{h}-\sigma_{H}-\sigma_{v}+2 v \sigma_{H}-2 v \sigma_{h}$ \\
\hline
\end{tabular}




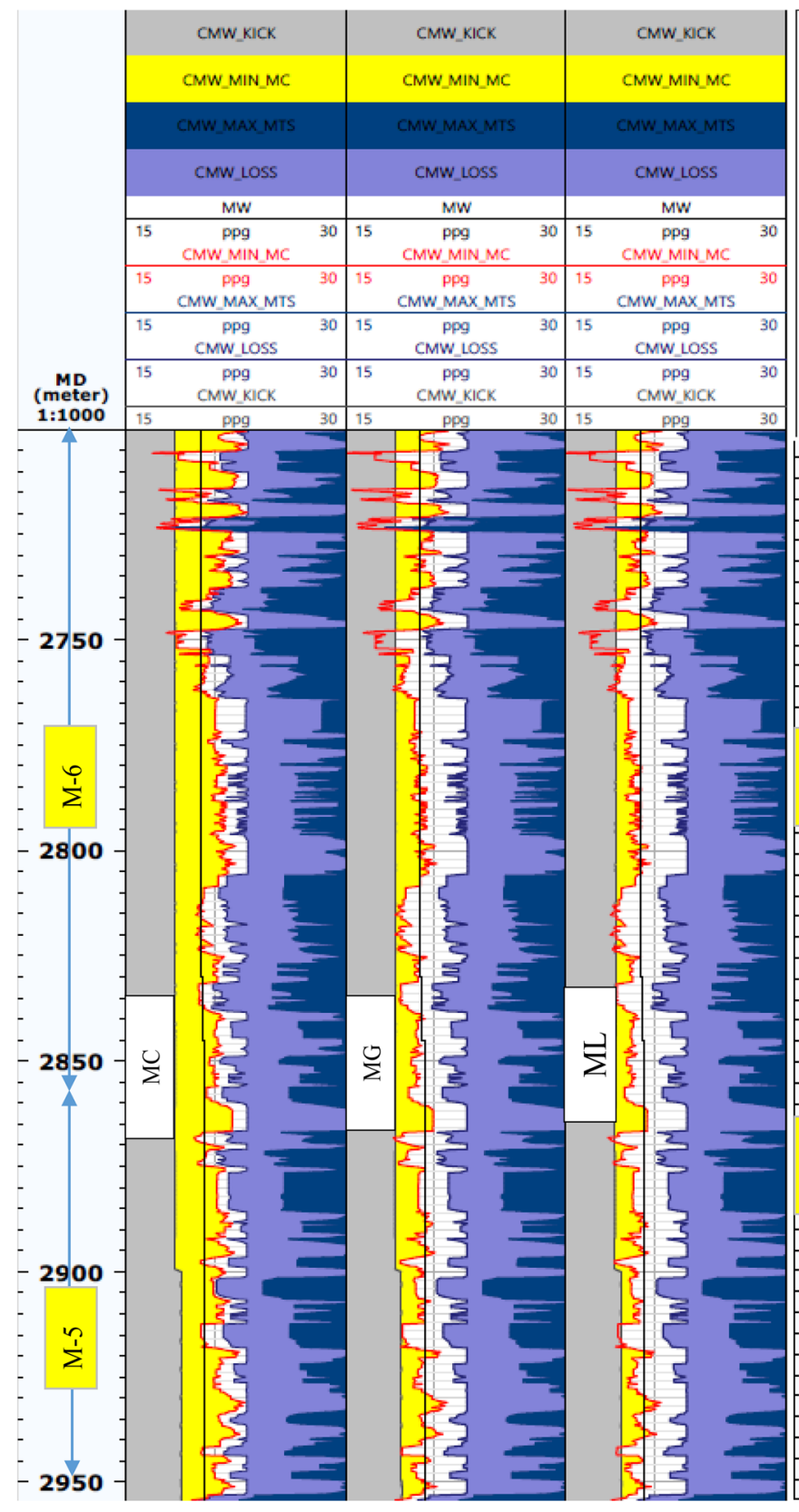

(a)

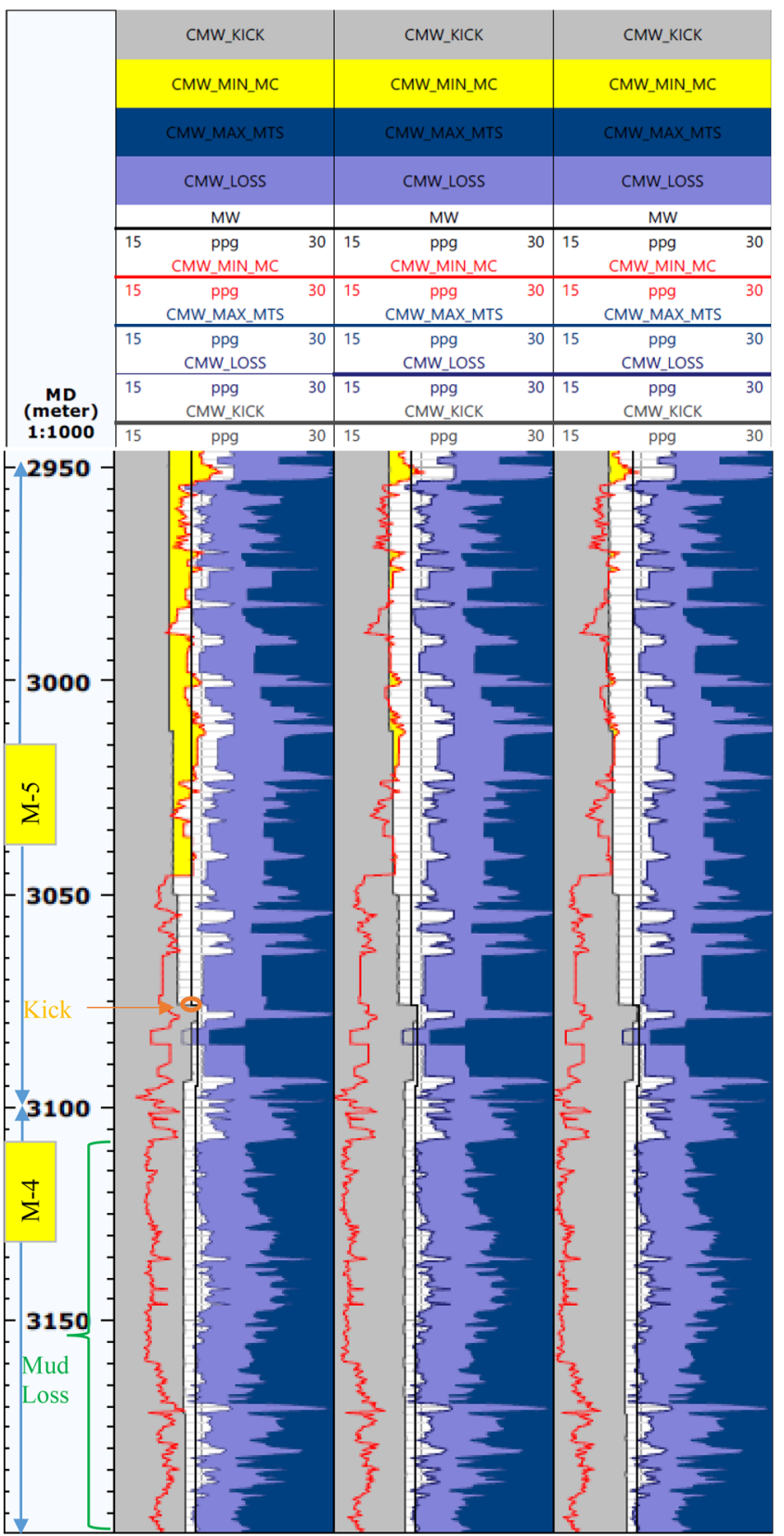

(b)
Fig. 13 a Safe mud weight window for Gachsaran formation (Kupal field, well Z26) using several shear failure criteria: Mohr-Coulomb, MC; Mogi-Coulomb, MG; and Modified Lade, ML (2700-2950 m). CMW_Kick shows the mud weights region where kicks can occur; CMW_Min shows the mud weights region where shear failure can

According to the results, Table 16 displays the polar plots of the drilling mud weight (at four arbitrary depths) to prevent onset shear and tensile failures in Gachsaran formation. The plots show the optimum mud weight distribution for each inclination and azimuth. It is inferred from the shear failure polar plot that we require a lower drilling mud weight for deviated holes in the direction of maximum occur; CMW_Max shows the mud weights region where tensile failure can occur; and CMW_Loss shows the mud weights region where mud loss can occur. b Safe mud weight window for Gachsaran formation for several failure criteria (2950-3200 m)

horizontal stress (particularly with the inclination angles greater than 40 degrees). Considering the tensile failure polar plot, the mud weight span is wider in the deviated holes to the maximum horizontal direction. Therefore, the mud weight can be safely selected high enough to overcome excessively high pore pressures of Gachsaran formation. It also signified that the shear failure would not be any 
Table 15 The ranges of boundaries of pore pressure, shear failure (for different failure criteria), mud loss and tensile failure (from the results of the safe mud weight window)

\begin{tabular}{llll}
\hline & Min & Mean & Max \\
\hline Pore pressure (ppg) & 18.33 & 18.94 & 20.72 \\
Shear failure, MC (ppg) & 16.42 & 19.98 & 23.34 \\
Shear failure, MG (ppg) & 14.64 & 18.61 & 22.08 \\
Shear failure, ML (ppg) & 14.23 & 18.25 & 21.67 \\
Mud loss (ppg) & 17.68 & 23.31 & 23.96 \\
Tensile failure (ppg) & 17.98 & 26.82 & 34.26 \\
\hline
\end{tabular}

issue for such deviated holes. However, practically, Gachsaran formation is preferred to be drilled vertically. This is because drilling of Gachsaran formation would add additional operational challenges such as solids settling. Next, the preference is to keep the $121 / 4$ " hole (across Gachsaran formation) vertical and then directionally open a window in the next hole section $(81 / 2 ")$ which is across the Asmari formation reservoir.

\section{Suggested field remedial actions}

In order to mitigate the wellbore stability issues and associated hole problems, it was recommended to drill the formation as quickly as possible. Therefore, CWD and CCS systems are designed as follows.

\section{Casing while drilling}

The tripping time of the casing string to the casing point is considerable in conventional drilling. This is detrimental to wellbore stability in a geomechanically unstable formation such as Gachsaran formation. The tripping time can contribute to a large number of drilling issues such as stuck casing or barite sag (i.e., settling of the mud weighting materials
Table 16 Polar plots of the mud weights for shear and tensile failures at four selected depths (using Mogi-Coulomb failure criterion)

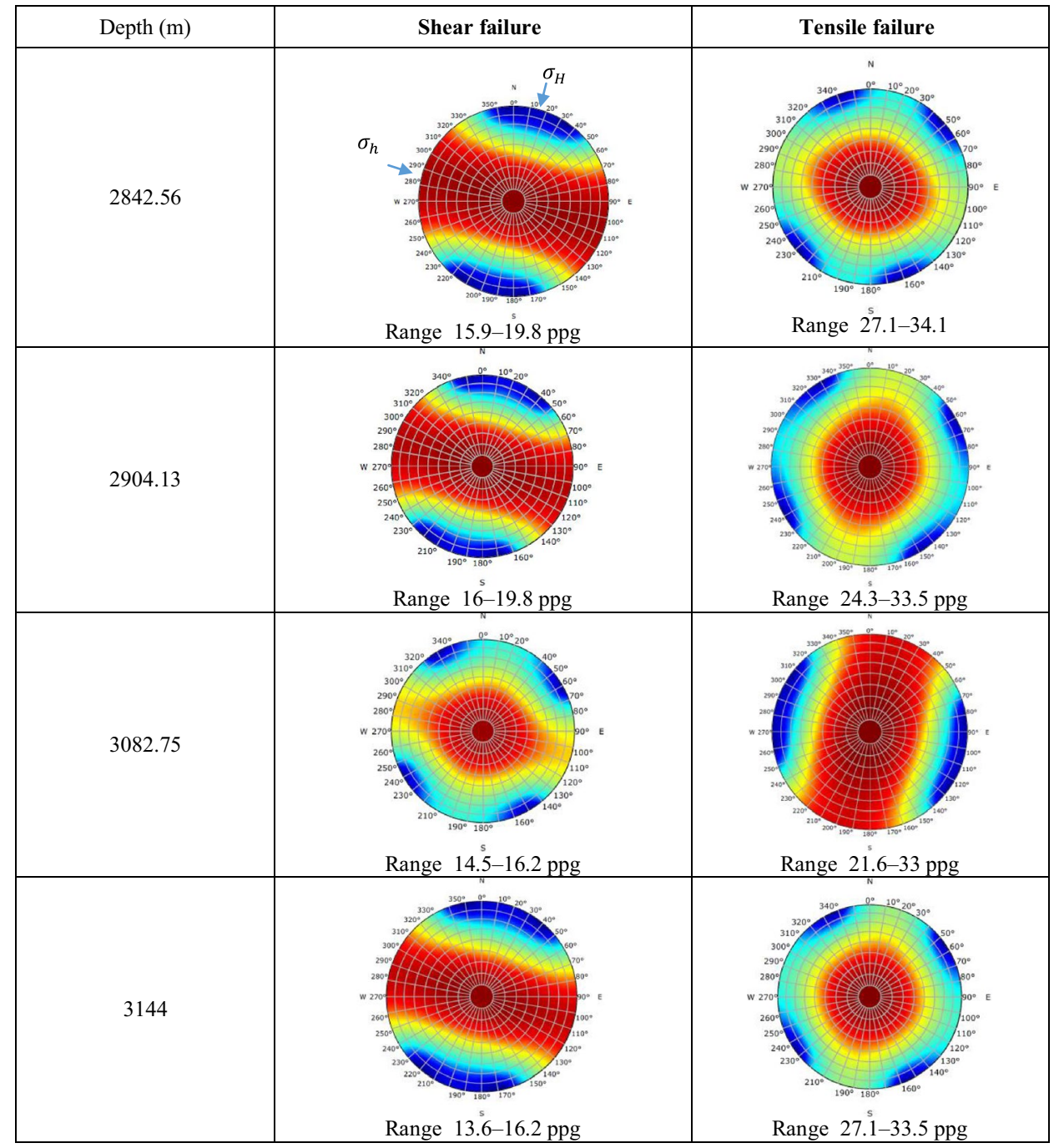




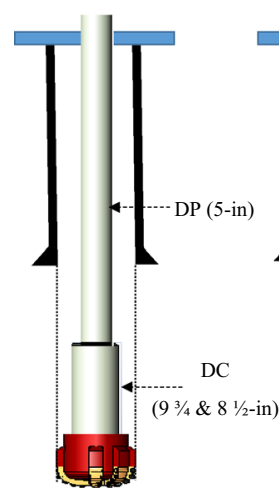

(a)

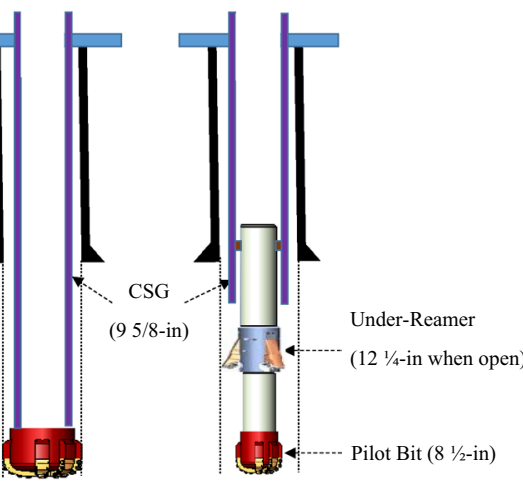

(b)

(c)
Fig. 14 a Conventional drill string, b non-retrievable CWD BHA and c retrievable CWD BHA for drilling the 12 1/4-in. hole

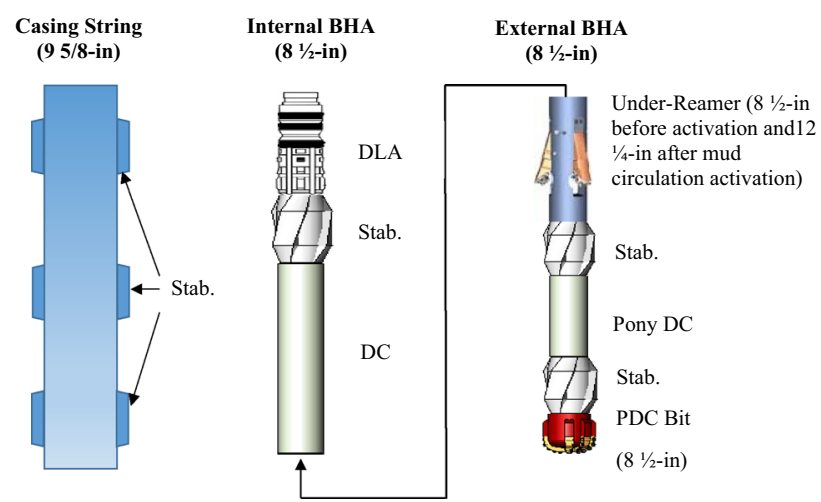

Fig. 15 Schematic of the drill string in casing while drilling (CWD) including the casing string (9 5/8-in.) and the BHA for deviation control in a vertical 12 1/4-in. hole of Kupal field (modified after Woods 2003; Mohammed et al. 2012)

and solids). Therefore, in addition to the drilling optimization, casing while drilling (CWD) system is proposed in order to eliminate this casing running time.

The CWD is a system which allows the casing to be installed in a well during the hole-making process. To make this happen, it uses the casing string as the drill string with the bit. This system contributes to elimination of the casing trip time. Thus, following drilling, the hole can be immediately cemented and properly sealed. In addition, it provides the plastering effect, i.e., strengthening of the wellbore and the mud cake, which contributes to mud loss mitigation (Woods 2003).

The high cost of CWD limits its use only in special cases when safe drilling using conventional systems is severely challenged due to the numerous drilling hazards. An example is drilling in formations with severe wellbore stability issues such as unexpected lost circulation and mud losses particularly with narrow and variable safe mud window, as is the case in this study. Another example can be drilling in formations with high-swelling shale, mainly caused by the time-dependent chemical wellbore instability. The unexpected drilling problems can largely be mitigated due to the advantages of CWD, including elimination of the trip time and for its plastering effect. Therefore, safe and optimized drilling can be viable in such formations.

\section{CWD design}

CWD is offered in two possible designs: (a) drillable bit and (b) retrievable dual-body bit, whereby the dual-body bit can be retrieved via wireline. In the $12^{1 / 4}$-in. hole section of Kupal field, due to the frequent hole problems, an unprecedented pulling out of the hole may become essential before reaching the casing point (due to equipment failure, e.g., the bit can become dull especially during drilling anhydrite, or it may become balled-up by the marl). Therefore, the retrievable CWD option is proposed in our case as it provides the capability to replace failed equipment and it is a cheaper option (Woods 2003). In the retrievable CWD, the drill string consists of (see Figs. 14 and 15):

- $81 / 2$-in. pilot bit The pilot bit is the lower part of the dualbody bit system (at the bottom of the string).

- Under-reamer The under-reamer is the upper part of the dual-body bit system. It is expanded to its full size (12 1/4-in.) as soon as mud circulation is started bottomhole (to enable enlarging the under-reamer size to

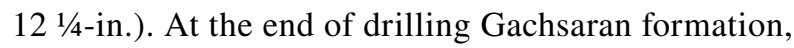
prior to retrieval (with wireline), upon stop of the mud circulation, the under-reamer reverts back to its initial size $\left(8^{1 / 2-i n .)}\right.$.

- DLA (drill lock assembly) It works as the connector of the casing string to the under-reamer.

- 95/8-in. casing string: The 9 5/8-in. casing string acts as the drill pipe. As the casing joints needs to stand the torsion and tension during drilling, their thread type must be VAM-TOP (which have extra tensile and torsion strength).

- Stabilizers Stabilizers are used between the pilot bit and under-reamer and in the casing string for deviation control of a vertical well, especially when there are intervals containing soft layers (as is the case with some intervals of Gachsaran formation in Kupal field).

\section{Required equipment for retrievable CWD}

There are several steps taken to make retrievable-CWD option possible. Therefore, first, the rig must appropriate

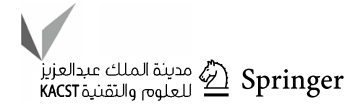




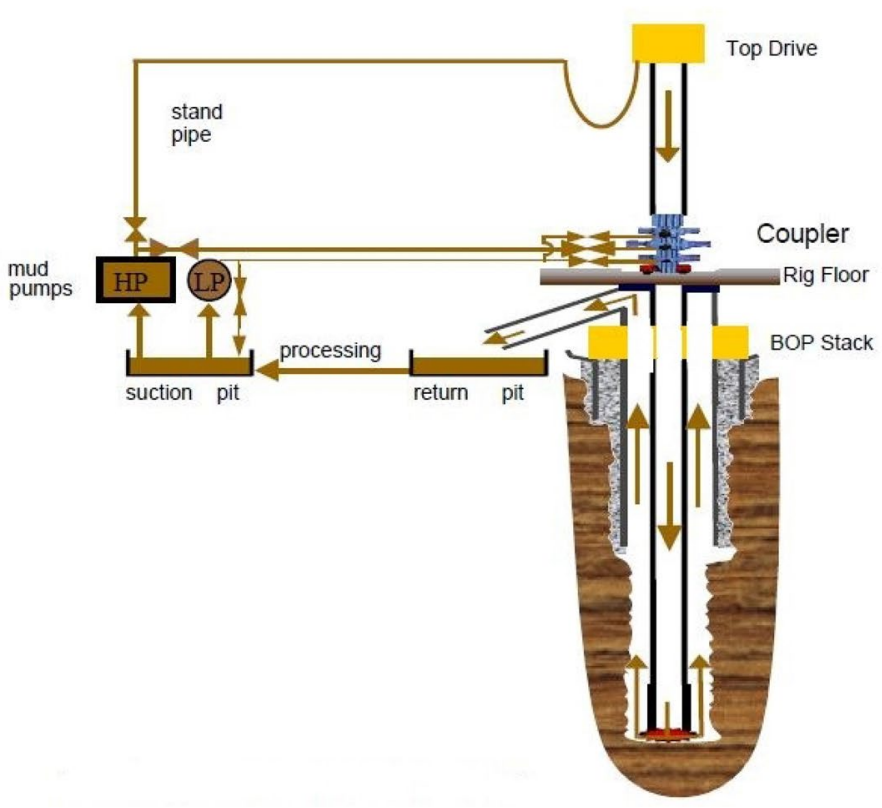

(a)

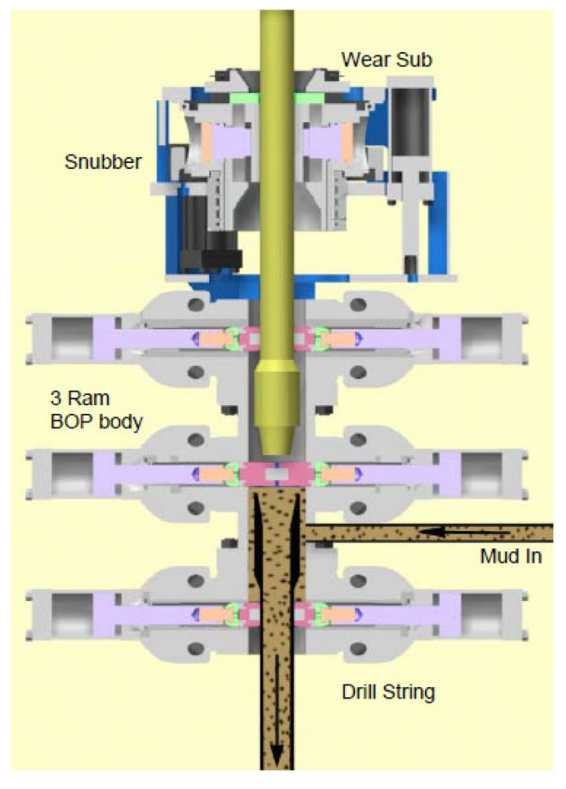

(b)

Fig. 16 a Mud flow circuit using a coupler installed at the rig floor and $\mathbf{b}$ cross-section of the coupler (Ayling et al. 2002)

specifications as stated below. Next, a wireline truck is required to retrieve the dual-body bit.

The drilling rig should have enough hook load capacity to be able to stand the weight of the casing string (used as the drill string). This should be met not only in buoyed condition (when the string is suspended), but also in dry condition (in case the string gets stuck and we need to apply overpull/tension to free it). Therefore, the maximum hook load must exceed the dry weight of the string. In

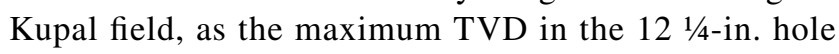
does not exceed $4000 \mathrm{~m}$, with the assumed $53.5 \mathrm{Ib} / \mathrm{ft}$ weight (ID of 8.535-in.) of the casing string, the minimum load would be nearly $700 \mathrm{~K}-\mathrm{Ib}$. Therefore, the currently active drilling rig in Kupal field (which has the hook load capacity of $1000 \mathrm{~K}-\mathrm{Ib}$ and power of $2000 \mathrm{hp}$ drawworks) has adequate hook load capacity for the CWD operation. Second, as the casing string is used in lieu of the drill string in CWD (with greater OD than the conventional drill string), the rotary table or top drive should provide or stand greater torques.

As the retrievable CWD design is found suitable in this field, a wireline truck (with enough weight and tension capacity) must be available at the rigsite to retrieve the dual-body bit prior to running and cementing the casing.

\section{Considerations for CWD Use}

The main limitation of using CWD to drill Gachsaran formation is the use of super-heavy mud with solid percentage reaching 50\% (to overcome the pore pressure gradients up to $22.32 \mathrm{ppg}$ ) which may cause possible stuck of the casing string during drilling. A possible measure to prevent this issue could be using an Expandable Tubular Technology. However, it is not possible to convert the $95 / 8$-in. casing to a liner in Kupal field as the 95/8-in. tubular must ultimately be extended to the surface due to the active tectonic forces of the field. It is noted that in 2003, this technology was already applied in one of the wells of this field (Yousafi et al. 2008) for running the 7 -in. liner in the $81 / 2$-in. hole (not the $95 / 8$ in. casing). Therefore, the necessary measures to prevent the mentioned problem is the use of high-quality mud materials (including weight materials such as barite and hematite and viscosifiers or polymers) to maintain the mud rheology and also using continuous circulation system (CCS) to prevent solid settling and kick flows during making connections.

\section{Continuous circulation system}

Continuous circulation system (CCS) is a model of managed pressure drilling (MPD) system to maintain the mud circulation during making connections (Ayling et al. 2002) with the dynamic mud pressure exceeding the formation pressure. It signifies that the well conditions can be maintained dynamic even during connections.

Application of CCS is essential in this field for several reasons. First, it can contribute to prevention of settling of the mud solids during connections, which is greatly important for CWD. Next, due to excessively high mud 
losses occurring in drilling Gachsaran formation, using the CCS system, ECD drilling should be commonly practiced (to mitigate extremely high mud losses encountered). Using conventional drilling system, circulation of drilling mud to the borehole has to stop to add a stand or joint of drill pipe to the drill string. Therefore, with the static mud column pressure lower than the formation pressure, kick flows occur during connections. Although the crew expedites in making the connections in such cases, the well records indicate that kick flows with 20-30 bbls pit gains have occurred. Therefore, it is essential to address this risky problem using CCS. To do this, as Fig. 16 shows, CCS simply requires a coupler (including a triple ram body which is installed at the rig floor) to allow the mud flow inlet and circulation from the mud pumps to the well as the drill pipe joint is added to (or removed) the drill string.

In some cases, mud pumps working with extremely high mud weights of up to 22.3 ppg may fail specially with in pumps with low-quality internal parts (such as seat and valve). It is noted that mud pump failure should be strictly prevented; otherwise, CWD or ECD drilling with CCS would fail and put the well at high risks.

\section{Conclusions}

In Kupal oilfield, drilling the cap rock of the oilfields faces numerous geomechanical challenges and lost times. To address the geomechanical challenges, this work has developed an MEM's workflow for a complex lithology formation by adjusting the equations/correlations to match with the core points and observations. The following items summarize the findings:

1. This is a pioneer wellbore stability work for the nonreservoir Gachsaran formation (with anhydrite, gypsum, marl and thin limestone layers). Therefore, such workflow is unique as it considers specific geomechanical and operational issues for such a complex lithology which are not available in other published MEM workflows. Having selected available correlations which are mostly for sandstones and carbonates, the constructed MEM was successfully calibrated using the available core data and field observations.

2. The results of the wellbore stability analysis in Kupal field indicated an excessively narrow safe mud weight window and over-pressured formation being the main cause of severe geomechanical drilling problems.

3. To mitigate the borehole problems, using the casing while drilling (CWD) and continuous circulation system (CCS) was proposed as a remedial action in order to prevent hole problems eliminating the geomechanical aspect of the lost times (30\% of the total lost times).

4. The CWD reduces the casing running time after drilling the hole section. The CCS enables mud circulation during pipe connections to prevent settling of super-heavy mud solids in CWD and prevent kick flows.

Open Access This article is licensed under a Creative Commons Attribution 4.0 International License, which permits use, sharing, adaptation, distribution and reproduction in any medium or format, as long as you give appropriate credit to the original author(s) and the source, provide a link to the Creative Commons licence, and indicate if changes were made. The images or other third party material in this article are included in the article's Creative Commons licence, unless indicated otherwise in a credit line to the material. If material is not included in the article's Creative Commons licence and your intended use is not permitted by statutory regulation or exceeds the permitted use, you will need to obtain permission directly from the copyright holder. To view a copy of this licence, visit http://creativecommons.org/licenses/by/4.0/.

\section{References}

Aadnoy BS (2003) Introduction to special issue on borehole stability. J Pet Sci Eng 38(3-4):79-82

Aadnoy BS, Looyeh R (2010) Petroleum rock mechanics: drilling operations and well design. Gulf Professional Publishing, Elsevier, Amsterdam

Aslannezhad M, Khaksar manshad A, Jalalifar H (2016) Determination of a safe mud window and analysis of wellbore stability to minimize drilling challenges and non-productive time. J Pet Explor Prod Technol 6:493-503. https://doi.org/10.1007/s1320 2-015-0198-2

Ayling LJ, Jenner JW, Elins H (2002) Continuous circulation drilling, OTC 14269. Presented at the offshore technology conference, 6-9 May, Texas, USA

Barton N (2006) Rock quality, seismic velocity, attenuation and anisotropy. Taylor and Francis, Oxford

Bell JS, Gough DI (1979) Northeast-Southwest compressive stress in Alberta: evidence from oil wells. Earth Planet Sci Lett 45:475-482

Blanton TL, Olson JE (1997) Stress magnitudes from logs: effects of tectonic strains and temperature. SPE-38719-MS, Presented at SPE annual technical conference and exhibition, 5-8 October, San Antonio, Texas

Bourgoyne AT, Millheim KK, Chenevert ME, Young FS (1986) Applied drilling engineering. SPE textbook series, vol 2 (ISBN: 978-1-55563-001-0)

Bowers GL (1994) Pore pressure estimation from velocity data: accounting for overpressure mechanisms besides undercompaction. SPE 27488. Society of Petroleum Engineers, Dallas, pp $515-589$

Bowes C, Procter R (1997) Drillers stuck pipe handbook, guidelines and drillers handbook credits. Schlumberger, UK

Bradley WB (1979) Failure of inclined boreholes. J Energy Res Technol Trans ASME 102:232

Chang C, Zoback M, Khaksar A (2006) Empirical relations between rock strength and physical properties in sedimentary rocks. J Pet Sci Eng 51(3-4):223-237 
Dugan B, Flemings PB (1998) Pore pressure prediction from stacking velocities in the Eugene Island 330 Field (Offshore Lousiana). Gas Research Institute, Chicago, p 23

Fjaer E, Holt RM, Raaen AM, Risnes R, Horsrud P (2008) Petroleum related rock mechanics, 2nd edn. Elsevier Science, Amsterdam

Goodman RE (1989) Introduction to rock mechanics. Wiley, Hoboken

Guo B, Ghalambor A (2002) Gas volume requirements for underbalanced drilling. Pennwell Corporation, Tulsa. ISBN 0-87814-802-7

Halliburton (2016) Reduce non-productive time (NPT). http://www. halliburton.com/en-US/ps/solutions/deepwater/challenges-solut ions/reduce-non-productive-time.page?node-id=hgjyd452\&Topic $=$ DeepwaterWestAfrica. Checked on 18 Nov 2016

Holt RM (2013) Static and dynamic moduli-so equal, and yet so different. Presented at the 47th US rock mechanics symposium held in San Francisco, CA, USA, 23-26 June

Jaeger JC, Cook NGW (1979) Fundamentals of rock mechanics, 2nd edn. Chapman and Hall, New York

Jaeger JC, Cook NGW, Zimmerman RW (2007) Fundamentals of rock mechanics, 4th edn. Blackwell Publishing, pp 221-228

Kirsch G (1898) Die Theorie der Elastizitat und die Bedurfnisse der Festigkeitslehre. Zeitschrift des Verlines Deutscher Ingenieure. 42:707

Kolawole O, Federer-Kovács G, Szabó I (2018) Formation susceptibility to wellbore instability and sand production in the Pannonian Basin, Hungary. American Rock Mechanics Association, Alexandria

Lama RD, Vutukuri VS (1978) Handbook on mechanical properties of rocks. Trans Tech Publications, Clausthal

Larsen I, Fjaer E, Renlie L (2000) Static and dynamic Poisson's ratio of weak sandstones. In: ARMA-2000-0077, 4th North American rock mechanics symposium, 31 July-3 August, Seattle, Washington

Lockner DA, Byerlee JD (1995) An earthquake instability model based on faults containing high fluid-pressure compartments. PAGEOPH 145:717-745. https://doi.org/10.1007/BF00879597

Mavko G, Mukerji T, Godfrey N (1995) Predicting stress-induced velocity anisotropy in rocks. Geophysics 60:1081-1087. https:// doi.org/10.1190/1.1443836

Meyer JJ (2002) The determination and application of in situ stresses in petroleum exploration and production. Submitted in fulfilment of the requirement for the $\mathrm{PhD}$ in National Centre for Petroleum Geology and Geophysics, Faculty of Science, The University of Adelaide

Militzer H, Stoll R (1973) Einige Beitrageder geophysics zur primadatenerfassung im Bergbau, Neue Bergbautechnik. Lipzig 3:21-25

Mody FK (2013) Bridging the gap: challenges in deploying leading edge geomechanics technology to reducing well construction costs. In: SPE/IADC Indian drilling technology conference and exhibition. Mumbai, India, 16 October 2006. Society of Petroleum Engineers

Mohammed A, Okeke CJ, Abolle-Okoyeagu I (2012) Current trends and future development in casing drilling. Int J Sci Technol 2(8):567-582

Mouchet JP, Mitchell A (1989) Abnormal pressures while drilling: origins, prediction, detection, evaluation. Elf EP-Editions, Editions Technip, Paris

Plona TJ, Cook JM (1995) Effects of stress cycles on static and dynamic Young's moduli in Castlegate sandstone. In: ARMA-950155 , Presented at the 35 th U.S. symposium on rock mechanics (USRMS), 5-7 June. Reno, Nevada
Plumb R (1994) Influence of composition and texture on the failure properties of clastic rocks. In: SPE 28022-MS, Rock mechanics in petroleum engineering, 29-31 August, Delft, Netherlands

Rehm WA, McClendon MT (1971) Measurement of formation pressure from drilling data. SPE 3601, Presented at the SPE annual fall meeting, New Orleons, 3-6 October

Sayers C, Nagy Z, Vasudev S, Tagbor K, Hooyman P (2009) Determination of in situ stress and rock strength using borehole acoustic data. SEG Technical Program

Schlumberger (2016) Real-time drilling geomechanics. http://www. slb.com/ /media/Files/dcs/product_sheets/geomechanics/geome chanics_rt_ps.pdf. Checked on 18 Nov 2016

Sinha BK, Vissapragada B, Renlie L, Skomedal E (2006) Horizontal stress magnitude estimation using the three shear moduli-a norwegian sea case study. Soc Petrol Eng. https://doi. org/10.2118/103079-MS

Simangunsong RA, Villatoro JJ, Davis AKM (2006) Wellbore stability assessment for highly inclined wells using limited rockmechanics data. SPE-99644. Presented at the 2006 SPE annual technical conference and exhibition, San Antonio, Texas, USA, 24-27 September

TerraTek Inc. (1998) The difference between static and dynamic mechanical properties. TerraTek Standard Publications, Salt Lake City

Wang Z (2000) Dynamic vs. static properties of reservoir rocks. In: Wang Z, Nur A (eds) Seismic and acoustic velocities in reservoir rocks, vol 3: recent developments. SEG, Tulsa

Wang Y, Watson R, Rostami J et al (2014) Study of borehole stability of Marcellus shale wells in longwall mining areas. J Pet Explor Prod Technol 4:59-71. https://doi.org/10.1007/s1320 2-013-0083-9

Woods JD (2003) Casing while drilling handbook. Gulf Publishing Company, Houston

York PL, Prichard DM, Dodson JK, Dodson T, Rosenberg SM, Gala D, Utama B (2009) Eliminating non-productive time associated with drilling through trouble zones. In: Offshore technology conference. Houston, Texas, 2009-05-04

Yousafi Y, Fazaelizadeh M, Hareland G, Kustamsi A, Mirhaj SA, Shirkavand F (2008) Cost evaluation of the first running experience of expandable openhole liner for unexpected problems in drilling well, Iran. SPE 114687, Presented at the IADC/SPE Asia Pacific drilling technology conference and exhibition, Jakarta, Indonesia, 25-27 August

Zamora M (1972) Slide rule correlation aids d-exponent use. Oil Gas J 70(51):68-72

Zhang J (2011) Pore pressure prediction from well logs: methods, modifications, and new approaches. Earth Sci Rev 108(1-2):50-63

Zhang J, Yu M, Al-Bazali TM, Ong S, Chenevert ME, Sharma MM, Clarc DE (2006) Maintaining the stability of deviated and horizontal wells: effects of mechanical, chemical, and thermal phenomena on well designs. SPE-100202, Presented at the 2006 SPE international oil and gas conference and exhibition, Beijing, China, 5-7 December

Zoback M (2010) Reservoir geomechanics. Cambridge University Press, Cambridge

Publisher's Note Springer Nature remains neutral with regard to jurisdictional claims in published maps and institutional affiliations. 